\title{
Miniature protein ligands for EVH1 domains: Interplay between affinity, specificity, and cell motility ${ }^{\perp}$
}

\author{
Jennifer H. Holtzman ${ }^{\ddagger}$, Kamil Woronowicz $^{\dagger}$, Dasantila Golemi-Kotra ${ }^{\dagger}$, and Alanna \\ Schepartz $\dagger, \ddagger$ \\ $\dagger$ Department of Chemistry, Yale University, New Haven, CT 06511 \\ $\$$ Department of Molecular, Cellular and Developmental Biology, Yale University, New Haven, Connecticut \\ 06520-8107.
}

\section{Abstract}

Dynamic rearrangements of the actin cytoskeleton power cell motility in contexts ranging from intracellular microbial pathogenesis to axon guidance. The Ena/VASP family proteins--Mena, VASP, and Evl--are believed to control cell motility by serving as a direct link between signaling events and the actin cytoskeleton. Our lab has previously reported a novel miniature protein, pGolemi, which binds with high affinity to the EVH1 domain of Mena (Mena $\left.{ }_{1-112}\right)$ but not to those of VASP $\left(\mathrm{VASP}_{1-115}\right)$ or $\mathrm{Evl}\left(\mathrm{Evl}_{1-115}\right)$ and also causes an unusual defect in actin-driven L. monocytogenes motility. Here, we use scanning mutagenesis to examine the effects of single amino acid changes within pGolemi on EVH1 domain affinity and specificity, miniature protein secondary structure, and L. monocytogenes motility. The data suggest that $\mathrm{pGolemi}$ contains the expected aPP-like fold and binds Mena ${ }_{1-112}$ in a manner highly analogous to the proline-rich repeat region of $L$. monocytogenes ActA protein. Residues throughout pGolemi contribute to both EVH1 domain affinity and paralog specificity. Moreover, the affinities of pGolemi variants for Mena ${ }_{1-112}$ correlate with selectivity against the EVH1 domains of VASP and Evl. In L. monocytogenes motility assays, speed and speed variability correlate strongly with EVH1 paralog specificity, suggesting that the Ena/VASP paralogs do not play equivalent roles in the process of L. monocytogenes actin tail maturation.

\section{Keywords}

pGolemi; EVH1; Mena; VASP; Evl; L. monocytogenes; motility; actin; cytoskeleton; alanine scan

The actin cytoskeleton is a complex system that transduces multiple converging signals into changes in the dynamics and architecture of actin assembly. An important family of direct regulators of the actin cytoskeleton, the Ena/VASP proteins are implicated in an astounding array of actin-based biological functions, reviewed in (1-8). These functions include the formation of cell membrane protrusions, particularly lamellipodia and filopodia, that are the

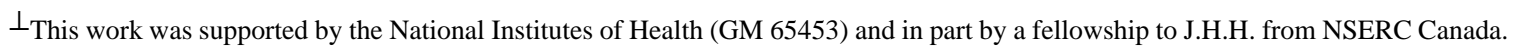
CORRESPONDING AUTHOR FOOTNOTE: Correspondance should be addressed to: phone, 203-432-8276; fax, 203-432-3486; email, alanna.schepartz@yale.edu..

BRIEFS A scanning mutagenesis study of a miniature protein ligand for Mena1-112 reveals the contributions of discrete amino acids to binding affinity, paralog specificity, and the disruption of L. monocytogenes motility.

SUPPORTING INFORMATION AVAILABLE

Procedures for protein expression, peptide synthesis and purification, $K_{\mathrm{d}}$ determination, $\mathrm{CD}$, and motility analysis. This information is available free of charge via the Internet at http://pubs.acs.org.
} 
hallmarks of amoeboid crawling motility in neuronal growth cones and fibroblasts during wound healing; platelet aggregation; formation of the T cell receptor immunological synapse; formation of focal adhesions and stress fibers during cell spreading; and motility of intracellular pathogens, such as L. monocytogenes.

The Ena/VASP family proteins include three paralogs in vertebrates: Mena, VASP, and Evl (9-12). These proteins share an overall three-part domain organization consisting of an Nterminal EVH1 domain, a central domain containing proline-rich sequences, and a C-terminal $\mathrm{EVH} 2$ domain $(4,13)$. The EVH1 domain is involved in recruitment of Ena/VASPs to their site of activity by specific interaction with proline-rich sequences in its binding partners. The central domain of the Ena/VASPs contains one or more phosphorylation sites depending on the particular paralog or splice variant $(11,14-17)$. This region is also rich in proline and serves as a docking site for proline recognition domains such as profilin and SH3 domains (10, 18-21). The C-terminal EVH2 domain is responsible for multiple functions, including oligomerization of the Ena/VASPs through a coiled coil domain (22), binding to both actin monomers and filaments, and, in VASP and Mena, these functions are modulated by phosphorylation (16,23-26).

Much effort has been devoted to studying the structure and function of the EVH1 domains and their interactions with proline-rich sequences (PRSs). PRSs are also recognized by several unrelated domains such as the SH3 (27-29), WW (29-31), GYF $(32,33)$, and UEV $(34,35)$ domains as well as the single domain protein profilin (36-38). Proline mediated interactions tend to be low affinity $(1-500 \mu \mathrm{M}$ range $)(39,40)$, a feature that allows macromolecular complex assembly and disassembly to respond to internal and extracellular signals on a rapid timescale. Ligands for proline recognition domains share a number of features, most importantly the ability to adopt a type II polyproline (PPII) helix that positions the cyclic pyrrolidine side chains on one helical face into grooves bounded by aromatic residues in the EVH1 domain binding pocket. Contacts arising from non-proline residues that extend the core binding epitope confer specificity and augment affinity (40). Four classes of homologous EVH1 domains have been structurally characterized to date $(5,41-43)$, and the residue preferences and binding orientation have been determined for three of these. For the EVH1 domains of Ena/VASP proteins, termed class I domains, the register or binding mode is determined by an aromatic or leucine residue in the second position of the consensus sequence (D/E)(F/L/W/Y)PX $\phi \mathrm{PX}_{1-3}$, where $\mathrm{X}$ can be any amino acid and $\phi$ is a residue with a hydrophobic side chain. Class II EVH1 domains found in the Homer/Vesl family proteins implicated in synaptic plasticity (44) recognize the consensus PPxxF, although the binding orientation is the same as class I ligands. The third class is comprised of WASP and N-WASP. The only known ligand for this domain is a 25residue peptide from WIP (WASP-interacting protein) that contains an LPPPEP motif. The structure for this complex was solved using a fusion construct of the two binding partners, and the ligand orientation was opposite to that of the examples mentioned above (41). No ligands are known for the class IV EVH1 domains found in Spred and Sprouty proteins that modulate tyrosine kinase signaling (43). Structural data is now available for representatives of each class of EVH1 domain (41-46), and alignment of the backbone residues shows the structures to be virtually superimposable.

Although the determinants of specificity between classes of proline recognition domains have been well studied, little is known about subtle differences between paralogs from the same class. This dearth of information arises because it is difficult to design molecules that possess sufficient specificity to discriminate between protein paralogs while retaining high affinity (47). Significant progress towards that goal in the context of EVH1 domain recognition was achieved with the initial characterization of pGolemi, a well-folded 30-residue polypeptide that exhibits high affinity for the Mena EVH1 domain (Mena ${ }_{1-112}$ ) and high paralog specificity. pGolemi was obtained by substituting six residues from the sequence of a known EVH1 ligand, 
the first proline-rich repeat of the L. monocytogenes ActA protein, for six judiciously chosen residues of the N-terminal PPII helix and $\beta$-turn regions of avian pancreatic polypeptide (aPP). The strategy used to design pGolemi has been successfully used by our lab (47-56) and others (57-60) to generate high affinity ligands for shallow surfaces that are often difficult to target using smaller molecules. The resulting miniature protein bound Mena ${ }_{1-112}$ with high nanomolar affinity, a 10-fold improvement over the previously reported highest affinity ligand, an 11-residue peptide from ActA $\left(\operatorname{Act}_{11}\right)$ (42). pGolemi bound with low affinity to the EVH1 domains of the two other Ena/VASP paralogs, VASP $\left(\mathrm{VASP}_{1-115}\right)$ and Evl $\left(\operatorname{Evl}_{1-115}\right)$, with equilibrium dissociation constants respectively 20 -fold and more than 100 -fold higher than for Mena $_{1-112}$.

In addition to achieving a high level of paralog specificity, pGolemi was unique because of the dramatic effect it had on the motility of L. monocytogenes in cell-free extracts, a wellestablished system for studying the actin polymerization motor. In the presence of pGolemi, L. monocytogenes assumed a discontinuous actin comet tail characterized by overall slowed motility and alternating bursts and lulls in speed that correlate to a bright and dark regions of the rhodamine-labeled actin tail, giving it an overall punctate appearance and the emergence of "hopping." Discontinuous comet tails during actin-based L. monocytogenes motility at steady state have been reported previously in cell extracts (61) and cultured mammalian cells (62) as well as in the context of ActA-coated beads in a mixture of purified proteins (63). A study of the process of L. monocytogenes motility initiation showed that "hopping" is a characteristic step in the establishment of robust tails to support continuous forward motion (64). In contrast to the effect of $\mathrm{pGolemi}, \mathrm{Act}_{11}$ failed to produce discontinuous tails at any concentration tested.

In light of these results, we sought to better characterize the biochemical and structural basis for pGolemi binding, paralog specificity, and the relationship of these recognition events to the motility aberrations reported previously. To this end, a series of pGolemi variants was synthesized. Each member of the series contained a single amino acid substitution at a position expected to play a role in Mena ${ }_{1-112}$ EVH1 binding or protein folding. The effects of these changes on binding EVH1 domain paralogs and on protein secondary structure were measured. Finally, L. monocytogenes motility assays were performed using a judiciously chosen set of variants to test the hypothesis the discontinuous tail phenotype is related to pGolemi's specificity.

\section{RESULTS}

\section{Identification of pGolemi variants}

To study the energetic contribution of individual pGolemi side chains to EVH1 affinity, specificity, and cell motility, we synthesized 18 pGolemi variants in which a single residue was substituted with alanine and used quantitative binding assays to determine the affinity of each variant for the EVH1 domains within Mena (Mena $\left.{ }_{1-112}\right)$, VASP (VASP $\left.{ }_{1-115}\right)$, and Evl $\left(\mathrm{Evl}_{1-115}\right)$, as detailed in the supplementary materials (65). We also prepared three additional variants, two in which a single proline residue at position 3 or 4 was replaced with sarcosine (abbreviated Z) and a third one containing leucine in place of Ala11. The equilibrium dissociation constants of the variant $\bullet M^{-1} a_{1-12}$ complexes determined in this way ranged from $800 \mathrm{nM}$ to $>100 \mu \mathrm{M}$, corresponding to free energies $\left(\Delta \mathrm{G}_{\mathrm{Mena}}\right)$ that vary over $3 \mathrm{kcal}^{\circ} \mathrm{mol}^{-1}$ (Table 1).

\section{Recognition of Mena ${ }_{1-112}$ by pGolemi variants}

The Mena 1 -112, affinity of each variant shown in Table 1 was determined using a tryptophan fluorescence perturbation assay, as described previously $(66,67)$. The Mena $1-112$, complexes 
formed from these variants were characterized by dissociation constants between $800 \mathrm{nM}$ and $>100 \mu \mathrm{M}$, which correspond to binding free energies between -8.3 and $>-5.8 \mathrm{kcal} \cdot \mathrm{mol}^{-1}$

(Figure 2A). Two pGolemi variants, P7A and F19A, reproducibly showed ill-behaved tryptophan perturbation profiles and were not included in further analysis. None of the pGolemi variants bound Mena ${ }_{1-112}$ with higher affinity than did pGolemi (Table 1, Figure 2A), although several showed altered paralog specificity (vide infra).

\section{Role of residues derived from Act $_{11}$}

First we consider pGolemi variants containing alanine in place of a residue derived from the L. monocytogenes protein ActA, namely F2A, P3A, P6A, E9A, and E10A. All of these residues are located on the N-terminal PPII helix of pGolemi. Of the five, the lowest affinity is seen with F2A $\left(\mathrm{K}_{\mathrm{d}}=55 \pm 6 \mu \mathrm{M}\right)$, whose complex with Mena ${ }_{1-112}$ is $2.7 \mathrm{kcal}^{\circ} \mathrm{mol}^{-1}$ less stable than the complex with pGolemi. P6A also binds Mena 1 -112 poorly $\left(\mathrm{K}_{\mathrm{d}}=9 \pm 2 \mu \mathrm{M}\right)$, a 1.6 $\mathrm{kcal} \cdot \mathrm{mol}^{-1}$ loss relative to pGolemi. The remaining alanine variants, P3A, E9A, and E10A, as well as the sarcosine variants $\mathrm{P} 3 \mathrm{Z}$ and $\mathrm{P} 4 \mathrm{Z}$, bind $\mathrm{Mena}_{1-112}$ with affinities that are comparable to that of pGolemi. Interesting, a pGolemi variant containing an additional ActA-derived leucine in place of Ala11 (A11L) was a poor ligand for Mena ${ }_{1-112}\left(\mathrm{~K}_{\mathrm{d}}=12 \pm 2 \mu \mathrm{M}\right.$, $\left.\Delta \Delta \mathrm{G}_{\text {Mena }}=1.8 \mathrm{kcal} \cdot \mathrm{mol}^{-1}\right)$.

\section{Role of residues derived from aPP}

Next, we consider those eight variants (P1A, P4A, F7A, F19A, L16A, L23A, Y26A, V29A) in which alanine is substituted for a residue that likely contributes to formation of the pGolemi hydrophobic core based on the crystal structure of aPP. This structure shows a core comprised of side chains from residues at positions 5, 7, and 8 on the aPP PPII helix and residues 17, 20, and 24 on the $\alpha$-helix; these positions correspond to residues 4, 6, 7, 16, 19, and 23 on pGolemi (Figure 1). These eight variants displayed widely varying affinities for Mena ${ }_{1-112}$. Variants P1A, P4A, and Y26A formed complexes with Mena $1_{1-12}$ whose stabilities $\left(0.8 \mu \mathrm{M} \leq K_{\mathrm{d}} \leq 3.3\right.$ $\mu \mathrm{M}$ ) were virtually identical to that of the corresponding pGolemi complex. Variants L16A and V29A, however, formed complexes whose stabilities were moderately destabilized (14 $\mu \mathrm{M} \leq K_{\mathrm{d}} \leq 29 \mu \mathrm{M}$ ), and variants L7A, L19A, and L23A formed complexes whose stabilities could only be estimated $\left(K_{\mathrm{d}} \geq 50 \mu \mathrm{M}\right)$. In summary, substitution of ActA-derived residues of pGolemi located within the aPP PPII helix (Phe2, Pro3, Pro6) significantly disrupt binding to Mena $_{1-112}$, while altering residues in the $\beta$-turn region (Glu9, Glu10) do not. In general, substitutions of aPP-derived folding residues decrease binding if they are located in the center of the hydrophobic core, while those located near the termini do not. Overall, the affinity of variants for $\mathrm{Mena}_{1-112}$ domain ranged from 0.8 to $\geq 77 \mu \mathrm{M}\left(\Delta \mathrm{G}_{\mathrm{Mena}}\right.$, from -8.3 to $\geq-5.6$ $\mathrm{kcal} \cdot \mathrm{mol}^{-1}$ ), representing reductions in affinity, $\Delta \Delta \mathrm{G}_{\text {Mena }}$, ranging from 0.2 to 3.1 $\mathrm{kcal} \cdot \mathrm{mol}^{-1}$. In a previous study of p007 (an aPP-based miniature protein generated through a combination of design and evolution), affinity of the alanine variants for specific hsCRE DNA ranged from $1.5 \leq K_{\mathrm{d}} \leq 692 \mathrm{nM}\left(\Delta \mathrm{G}_{\mathrm{hSCRE}}=-12\right.$ to $\left.-8.4 \mathrm{kcal} \cdot \mathrm{mol}^{-1}\right)$ (54). It is notable that despite having dramatically different targets, variants of both miniature proteins cover a similar range of binding energy differences.

\section{Analysis of VASP binding by pGolemi variants}

The affinity of each pGolemi variant for the EVH1 domain of VASP (VASP ${ }_{1-115}$ ) was also determined using tryptophan perturbation analysis, as described above for Mena 1-112 $_{\text {(Table }}$ 1, Figure 2B). Four variants (P3A, P7A, F19A, and V29A) reproducibly showed ill-behaved binding to $\mathrm{VASP}_{1-115}$ and were not included in the analysis. Ten of the remaining variants bound VASP ${ }_{1-115}$ as well as or better than pGolemi $\left(K_{\mathrm{d}}=13 \pm 2 \mu \mathrm{M}\right)$ with affinities ranging from 1.3 to $10 \mu \mathrm{M}$ (Figure 2B). The highest VASP ${ }_{1-115}$ affinity was observed with variant T5A $\left(K_{\mathrm{d}}=1.3 \pm 0.2 ; \Delta \mathrm{G}=-8.0 \mathrm{kcal} \bullet \mathrm{mol}^{-1}\right)$. Substitution of leucine at position 5 , by contrast, gives 
a variant with the same affinity for $\mathrm{VASP}_{1-115}$ as pGolemi, within error, indicating that the residue identity at that position is important for $\mathrm{VASP}_{1-115}$ affinity. Of the substitutions that lead to decreased $\mathrm{VASP}_{1-115}$ affinity, two are for ActA-derived residues of pGolemi (F2A and P6A), and three are for aPP-derived folding residues in the $\alpha$-helix (L16A, L23A and Y26A). For the three $\alpha$-helix residues, only an upper limit was reported because the upper plateau of the binding curve is not reached.

\section{Analysis of Evl binding by pGolemi variants}

The affinity of pGolemi variants for the EVH1 domain of Evl (Evl $\left.1_{1-115}\right)$ was measured by tryptophan perturbation, as described above for $\mathrm{Mena}_{1-112}$ (Table 1, Figure 2B). Five variants showed ill-behaved binding to $\mathrm{Evl}_{1-115}$ and are not included in the analysis (P3A, P6A, P7A, F19A, and V29A). Although pGolemi does not detectably bind to Evl $1-115$ up to $100 \mu \mathrm{M}$ $\left(\Delta \mathrm{G}_{\text {Mena }}>-5.5 \mathrm{kcal} \bullet \mathrm{mol}^{-1}\right)$, eight variants with single amino acid substitutions show moderate affinity for this domain (Figure $2 \mathrm{C}$ ), ranging from 13 to $43 \mu \mathrm{M}\left(\Delta \mathrm{G}_{\mathrm{Mena}}=-6.7\right.$ to $\left.-6.0 \mathrm{kcal} \cdot \mathrm{mol}^{-1}\right)$. The variant with the highest affinity for $\operatorname{Evl}_{1-115}$ is T5A $\left(K_{\mathrm{d}}=13 \pm 2 \mu \mathrm{M}\right.$; $\left.\mathrm{G}=-6.7 \mathrm{kcal}^{-} \mathrm{mol}^{-1}\right)$. The corresponding leucine variant, T5L $\left(K_{\mathrm{d}}=22 \pm 1 \mu \mathrm{M} ; \mathrm{G}=-6.4\right.$ $\mathrm{kcal} \bullet \mathrm{mol}^{-1}$ ), has lower affinity. The sensitivity of this position to minor perturbations reveals a subtle role for this position on $\mathrm{Evl}_{1-115}$ affinity. Other variants that bind $\mathrm{Evl}_{1-115}$ in the 20-50 $\mu \mathrm{M}$ range include $\mathrm{P} 1 \mathrm{~A}$ and $\mathrm{P} 4 \mathrm{~A}$ (substitution of aPP-derived folding residues in the PPII helix); F2L, E9A, and E10A (ActA-derived residues); and A11L (aPP-derived non-folding residue). Of the variants that display low affinity for $\operatorname{Evl}_{1-115}$ by tryptophan perturbation $\left(K_{\mathrm{d}}>50 \mu \mathrm{M}\right)$, two have substitutions within ActA-derived residues (F2A and P3Z), and three have changes in aPP-derived folding residues (P4Z in the PPII helix; L16A, L23A, and Y26 A in the $\alpha$-helix).

\section{Analysis of paralog specificity: Mena vs. VASP}

The relative affinity of each variant for Mena and $\mathrm{VASP}_{1-115}$ was compared to gain insight into the relative contribution, direct or indirect, of each amino acid substitution to the overall paralog specificity of pGolemi. The variant whose specificity profile most closely resembles that of pGolemi $\left(\Delta \Delta \mathrm{G}_{\mathrm{SP} \text { Mena-VASP }}=-1.8 \mathrm{kcal} \bullet \mathrm{mol}^{-1}\right)$ is $\mathrm{Y} 26 \mathrm{~A}\left(\Delta \Delta \mathrm{G}_{\mathrm{SP} \text { Mena-VASP }}<-1.7\right.$ $\left.\mathrm{kcal} \bullet \mathrm{mol}^{-1}\right)$. Other variants exhibiting similar selectivity include P1A $\left(\Delta \Delta \mathrm{G}_{\mathrm{SP} \text { Mena-VASP }}=\right.$ $\left.-1.1 \mathrm{kcal}^{\circ} \mathrm{mol}^{-1}\right), \mathrm{E} 9 \mathrm{~A}\left(\Delta \Delta \mathrm{G}_{\mathrm{SP} \text { Mena-VASP }}=-1.3 \mathrm{kcal} \cdot \mathrm{mol}^{-1}\right), \mathrm{F} 2 \mathrm{~L}\left(\Delta \Delta \mathrm{G}_{\mathrm{SP} \text { Mena-VASP }}=-1.3\right.$ $\left.\mathrm{kcal} \bullet \mathrm{mol}^{-1}\right)$, and T5L $\left(\Delta \Delta \mathrm{G}_{\mathrm{SP} \text { Mena-VASP }}=-1.1 \mathrm{kcal} \bullet \mathrm{mol}^{-1}\right)$. The data suggest that the residues substituted in these cases do not contribute significantly to paralog specificity.

pGolemi variants whose specificity profiles differ from pGolemi fall into three categories. First, decreased affinity for both Mena ${ }_{1-112}$ and $\operatorname{VASP}_{1-115}\left(K_{\mathrm{d}}>50 \mu \mathrm{M}\right)$ is seen for two variants, F2A $\left(\Delta \Delta \mathrm{G}_{\mathrm{SP} \text { Mena-VASP }}=0 \mathrm{kcal} \bullet \mathrm{mol}^{-1}\right)$ and L23A $\left(\Delta \Delta \mathrm{G}_{\text {SP Mena-VASP }}<0.3\right.$ $\mathrm{kcal} \cdot \mathrm{mol}^{-1}$ ). This paralog-independent reduction in specificity, resulting from changes in both a presumed direct binding residue (Phe2) and a folding residue (Leu 23), emphasizes the role of the overall miniature protein fold in controlling the fidelity of EVH1 domain binding interactions.

Paralog-dependent differences in affinity arising from an increase in affinity for VASP $\mathrm{V}_{1-115}$ that may be coupled with decreased affinity for $\mathrm{Mena}_{1-112}$ are seen in a second category of variants. The most striking examples are $\mathrm{T} 5 \mathrm{~A}$ and $\mathrm{A} 11 \mathrm{~L}$, whose specificity profiles are the reverse of pGolemi's ( $\Delta \Delta \mathrm{G}_{\mathrm{SP} \text { Mena-VASP }}$ of 0.3 and $0.2 \mathrm{kcal} \cdot \mathrm{mol}^{-1}$, respectively). We note that both T5A and $\mathrm{A} 11 \mathrm{~L}$ are altered at aPP-derived non-folding residues. Two other variants that show less dramatic effects are $\mathrm{P} 3 \mathrm{Z}\left(\Delta \Delta \mathrm{G}_{\mathrm{SP} \text { Mena-VASP }}=-0.6 \mathrm{kcal} \cdot \mathrm{mol}^{-1}\right)$ and $\mathrm{E} 10 \mathrm{~A}$ $\left(\Delta \Delta \mathrm{G}_{\mathrm{SP} \text { Mena-VASP }}=-0.4 \mathrm{kcal} \cdot \mathrm{mol}^{-1}\right)$, which have substitutions at ActA-derived residues. By contrast, modestly reduced affinity for both Mena ${ }_{1-112}$ and $\mathrm{VASP}_{1-115}$ is the hallmark of a third category of variants. For example, variants P6A and L16A both show moderate affinity for $\operatorname{Mena}_{1-112}\left(K_{\mathrm{d} \text { Mena }}\right.$ is $9 \pm 2$ and $14 \pm 3 \mu \mathrm{M}$, respectively) while VASP ${ }_{1-115}$ affinity is decreased 
( $K_{\mathrm{d} \text { VASP }}$ is $34 \pm 3$ and $>50 \mu \mathrm{M}$, respectively). The resultant specificity phenotype is therefore similar to but less pronounced than that of pGolemi $\left(\Delta \Delta \mathrm{G}_{\text {SP Mena-VASP }}\right.$ is $-0.8 \mathrm{kcal} \cdot \mathrm{mol}^{-1}$ for P6A and $<-0.7 \mathrm{kcal} \cdot \mathrm{mol}^{-1}$ for L16A). The data suggest that the residue identities at positions $3,5,10$ and 11 contribute to paralog specificity primarily by modulating affinity for VASP $_{1-115}$, while those at positions 6 and 16 affect affinity for both Mena ${ }_{1-112}$ and VASP $_{1-115}$.

\section{Analysis of paralog specificity: Mena vs. Evl}

The same approach was taken to evaluate the relative roles of each amino acid substitution in determining specificity between $\mathrm{Mena}_{1-112}$ and $\mathrm{Evl}_{1-115}$. Several variants recapitulate the pGolemi specificity profile (i.e., $\left.K_{\mathrm{d} \text { Mena }}<K_{\mathrm{d} \text { Evl }}\right)$, including P3Z $\left(\Delta \Delta \mathrm{G}_{\mathrm{SP} \text { Mena-Evl }}<-1.8\right.$ $\left.\mathrm{kcal} \bullet \mathrm{mol}^{-1}\right)$, P4Z $\left(\Delta \Delta \mathrm{G}_{\mathrm{SP} \text { Mena-Evl }}<-1.8 \mathrm{kcal}^{\circ} \mathrm{mol}^{-1}\right)$, and Y26A $\left(\Delta \Delta \mathrm{G}_{\text {SP Mena-Evl }}<-2.3\right.$ $\left.\mathrm{kcal} \cdot \mathrm{mol}^{-1}\right)$, but none show the same dramatic difference in affinity between Mena $1-112$ and $\operatorname{Evl}_{1-115}$ as pGolemi $\left(\Delta \Delta \mathrm{G}_{\mathrm{SP} \text { Mena-Evl }}<-3.1 \mathrm{kcal} \bullet \mathrm{mol}^{-1}\right)$. This observation suggests that these three residue positions are not implicated in Mena-Evl specificity. As was seen in the MenaVASP analysis, substitution of Phe2 or Leu 23 for Ala decreases Mena-Evl specificity by a paralog-independent mechanism in that affinity is greater than $50 \mu \mathrm{M}$ for both domains. This result further underscores the importance of the residue identity at these positions in establishing basal EVH1 affinity. Variants with substitutions for other residues also maintain the general specificity profile of pGolemi but exhibit a range of intensities. An increase in affinity for $\mathrm{Evl}_{1-115}$ accompanied by little or no difference in $\mathrm{Mena}_{1-112}$ affinity is seen in variants with substitutions for ActA-derived residues (F2L: $\Delta \Delta \mathrm{G}_{\text {SP Mena-Evl }}=-1.9$ $\mathrm{kcal} \cdot \mathrm{mol}^{-1}$; E9A: $\Delta \Delta \mathrm{G}_{\mathrm{SP} \text { Mena-Evl }}=-2.2 \mathrm{kcal} \cdot \mathrm{mol}^{-1}$; E10A: $\Delta \Delta \mathrm{G}_{\mathrm{SP} \text { Mena-Evl }}=-1.9$ $\mathrm{kcal}^{\circ} \mathrm{mol}^{-1}$ ), as well as for an aPP-derived PPII-helix folding residues (P1A: $\left.\Delta \Delta \mathrm{G}_{\mathrm{SP} \text { Mena-Evl }}=-1.9 \mathrm{kcal} \cdot \mathrm{mol}^{-1} ; \mathrm{P} 4 \mathrm{~A}: \Delta \Delta \mathrm{G}_{\mathrm{SP} \text { Mena-Evl }}<-1.5 \mathrm{kcal}^{-\mathrm{mol}^{-1}}\right)$ and a non-folding residue (T5A: $\Delta \Delta \mathrm{G}_{\mathrm{SP} \text { Mena-Evl }}=-1.0$; T5L: $\Delta \Delta \mathrm{G}_{\mathrm{SP} \text { Mena-Evl }}=-1.5 \mathrm{kcal}^{\circ} \mathrm{mol}^{-1}$ ). Reduced specificity is also observed upon substitution of an aPP-derived $\alpha$-helix folding residue, L16A $\left(\Delta \Delta \mathrm{G}_{\mathrm{SP} \text { Mena-Evl }}<-0.7 \mathrm{kcal} \cdot \mathrm{mol}^{-1}\right)$, resulting from decreased Mena ${ }_{1-112}$ affinity. In contrast, the loss of specificity of a variant in which an aPP-derived non-folding residue is changed, A11L $\left(\Delta \Delta \mathrm{G}_{\mathrm{SP} \text { Mena-Evl }}=-0.4 \mathrm{kcal} \cdot \mathrm{mol}^{-1}\right)$, is the result of a concurrent increase in $\mathrm{Evl}_{1-115}$ affinity $\left(K_{\mathrm{d}}=23 \pm 10 \mu \mathrm{M}\right)$ and decrease in Mena affinity $\left(K_{\mathrm{d}}=12 \pm 2 \mu \mathrm{M}\right)$. To summarize, the data suggest that the identity of residues throughout pGolemi impact Mena-Evl specificity primarily through modulation of Evl affinity (F2L, E9A, E10A, P1A, T5A), Mena affinity (L16A), or both (A11L).

\section{An alternate designed EVH1 domain-specific miniature protein: pGol-2}

We also explored an alternative design, pGol-2, that differs from pGolemi in terms of how the sequences of $\mathrm{Act}_{11}$ and aPP are aligned and by the addition of a glutamate residue at the $\mathrm{N}$ terminus that has been shown to improve the affinity of peptide ligands for EVH1 domains (46) (Figure 1B). Interestingly, pGol-2 shows the reverse specificity profile of pGolemi (Table 1): no binding to $\mathrm{Mena}_{1-112}$ is detected at concentrations as high as $100 \mu \mathrm{M}$, while the

VASP $_{1-115}$ affinity is comparable to pGolemi. Moreover, the affinity of pGol-2 for $\mathrm{Evl}_{1-115}$ is higher than for any of the pGolemi variants $\left(K_{\mathrm{d}}=10 \pm 2 \mu \mathrm{M}\right)$.

\section{Secondary and tertiary structures of pGolemi variants}

The $\alpha$-helical content of each pGolemi variant was measured by circular dichroism spectroscopy (CD), and the mean residue ellipticities at $222 \mathrm{~nm}\left(\mathrm{MRE}_{222}\right)$ for each are reported in Table 1. In general, variants that retain significantly $\alpha$-helical character at $25{ }^{\circ} \mathrm{C}$ also melt cooperatively. With the exception of variant E9A $\left(\mathrm{T}_{\mathrm{m}}=54^{\circ} \mathrm{C}\right)$, none of the variants are better folded than pGolemi $\left(\mathrm{T}_{\mathrm{m}}=42^{\circ} \mathrm{C}\right)$. As expected, substitution of aPP-derived folding residues in variants P1A, P4A, P7A, L16A, F19A, L23A, and Y26A leads to a dramatic decrease in $\alpha$ - 
helix secondary structure. pGol- 2 is also well folded, with a greater $\alpha$-helix content $\left(\mathrm{MRE}_{222}\right.$ $\left.=-20,386 \mathrm{deg} \cdot \mathrm{cm}^{2} \mathrm{dmol}^{-1}\right)$ and a higher melting temperature $\left(\mathrm{T}_{\mathrm{m}}=50{ }^{\circ} \mathrm{C}\right)$ than pGolemi.

\section{Effect of pGolemi variants on L. monocytogenes motility}

The bacterium $L$. monocytogenes achieves motility by recruiting Ena/VASP proteins through a direct interaction with the $L$. monocytogenes cell surface protein ActA. A cell-free assay for L. monocytogenes motility in $X$. laevis oocyte extract has provided a valuable model system for studying mechanisms of actin cytoskeleton control $(68,69)$. In previous work, we reported that the presence of 10-27 $\mu \mathrm{M}$ pGolemi decreased by $68 \%$ the speed of L. monocytogenes motion in X. laevis oocyte extract (66), in agreement with results obtained when the EVH1 binding motifs were removed from ActA (70) (71-73) or when Ena/VASP proteins were removed from cell extracts (74). Additionally, pGolemi caused extreme speed variation and the formation of discontinuous actin comet tails. By contrast, the addition of a non-specific EVH1 domain ligand, an 11-residue peptide derived from the proline repeat region of ActA, at the same concentration results in a speed reduction of more than $85 \%(66,70,71)$ with no observed speed variation. We hypothesized that the discontinuous tails might result from the high paralog specificity observed in vitro. To test this hypothesis, a selection of miniature proteins showing a range of affinities towards the EVH1 domains of Mena $\mathrm{M}_{1-11}, \mathrm{VASP}_{1-115}$ and $\mathrm{Evl}_{1-115}$ were analyzed for their effects on L. monocytogenes median speed and speed variability (maximum/median speed ratio) (Figure 3 ). Under control conditions ( $\mathrm{aPP}_{1-31}$, or no miniature protein ligand), the median bacterial speeds is $0.10 \pm 0.03 \mu \mathrm{m} / \mathrm{second}$, which is comparable to literature reports of $0.10 \pm 0.01 \mu \mathrm{m} /$ second (68) and speed variability ratios is $1.20 \pm 0.08$. In the presence of $10 \mu \mathrm{M}$ pGolemi, the median speed is reduced by $83 \%$, as reported previously $(0.017 \pm 0.005, \mathrm{n}=46)(66)$, and the speed variability ratio was higher than that of all tested miniature proteins $(3.3 \pm 0.8)$. At $10 \mu \mathrm{M}$, only variant F2L showed a significant reduction in median speed $(69 \% ; 0.03 \pm 0.01 \mu \mathrm{m} / \mathrm{second} ; \mathrm{n}=62)$ and an increase in speed variability $(2.0 \pm 0.4)$ (Figure $3 \mathrm{~A}$ ). Surprisingly, pGol-2 at $10 \mu \mathrm{M}$ caused a significant $(\mathrm{p}<0.01)$ increase in median speed of $38 \%(0.14 \pm 0.03 \mu \mathrm{m} / \mathrm{second} ; \mathrm{n}=39)$; however, speed variability was similar to control. At $100 \mu \mathrm{M}$, pGolemi, F2A, and T5L showed a significant (p $<0.01$ ) decrease in median speed (pGolemi: $0.03 \pm 0.01 \mu \mathrm{m} /$ second, $\mathrm{n}=27$; F2A: $0.02 \pm 0.01$ $\mu \mathrm{m} /$ second; $\mathrm{n}=41$; T5L: $0.06 \pm 0.02 \mu \mathrm{m} / \mathrm{second} ; \mathrm{n}=23$ ) accompanied by an increase in speed variability (pGolemi: $3 \pm 1$; F2A: $2.3 \pm 0.6$; T5L: $1.9 \pm 0.2$ ). F2L caused a decrease in speed $(0.06 \pm 0.02 \mu \mathrm{m} / \mathrm{second} ; \mathrm{n}=28)$, but speed variability was comparable to control. In contrast, A11L and pGol-2 both caused significant $(\mathrm{p}<0.05)$ increases in median speed compared to controls at this concentration (A11L: $0.15 \pm 0.02 \mu \mathrm{m} / \mathrm{second}$; $\mathrm{n}=21$; pGol-2: $0.160 \pm 0.006$ $\mu \mathrm{m} / \mathrm{second} ; \mathrm{n}=7$ ), with speed variability comparable to control.

Plotting speed or speed variability against EVH1 domain affinity for these selected miniature proteins reveals unexpected trends (Figure 4). Increased affinity for Mena ${ }_{1-112}$ correlates weakly with decreased speed and increased speed variability of motile bacteria in the presence of miniature protein, while the reverse trends are observed for $\mathrm{Evl}_{1-115}$ affinity. There is no obvious relationship between $\mathrm{VASP}_{1-115}$ affinity and the motility of $L$. monocytogenes in these assays. The median speed and maximum:median speed ratios were also plotted against the EVH1 domain specificity of each miniature protein or variant specificity of between pairs of EVH1 domain paralogs to identify relationships between specificity and aberrant $L$. monocytogenes motility (Figures 5). A strong linear correlation was observed for both metrics at $10 \mu \mathrm{M}$ miniature protein, indicating that high specificity, particularly modest binding to VASP $_{1-115}$ and especially Evl ${ }_{1-115}$, is related to decreased speed and increased speed variability. These observations hold but are less striking for assays conducted using $100 \mu \mathrm{M}$ ligand. 


\section{pGolemi localizes to the actin tail-bacterium interface}

A fluorescently tagged analog of pGolemi was used to monitor localization under the conditions of the L. monocytogenes motility assay. At a concentration of $27 \mu \mathrm{M}$, pGolemi ${ }^{\mathrm{Flu}}$ appeared as a short, bright tail attached to the L. monocytogenes cell surface (Figure 6) that elongated as the bacterium accelerated forward. When a bacterium reached its maximum speed, the tail became detached from the surface. The observation that pGolemi, a ligand for the EVH1 domain of Mena, localizes to the actin surface at the interface between the bacterium and the comet tail is in agreement with previous studies that show that Ena/VASP proteins are localized at the distal pole of motile L. monocytogenes $(75,76)(11,77)$. Ena/VASPs act as indirect links by attaching to the proline-rich repeat region of the bacterial surface protein ActA through their EVH1 domain $(75,76)$ and also to actin filaments through the EVH2 domain (74). The tail can also attach directly to the bacterium by binding sites on ActA. The observation of the discontinuous tails in the presence of a specific inhibitor of EVH1 domain interactions suggests a weakening of the Ena/VASP-mediated molecular connections between the tail and the bacterium.

\section{DISCUSSION}

\section{pGolemi contains an aPP-like fold and binds the Mena EVH1 domain in a manner analogous to ActA $_{11}$}

Structural (42), biochemical $(72,78)$, and functional $(79,80)$ studies of Ena/VASP proteins have highlighted the critical importance of the aromatic residue of EVH1 domain ligands, both by its contribution to affinity through shape complementarity to a V-shaped pocket within the binding surface and by setting the correct register and orientation of the PPII helix (42), reviewed in (39). For unstructured peptide ligands, the aromatic residue can be substituted for any aromatic residue or leucine with little or no loss in affinity (42,46,72,81-83). pGolemi shows analogous behavior: the variant containing alanine in place of phenylalanine at position 2 (F2A) exhibits a dramatic loss in affinity for Mena ${ }_{1-112}$, whereas the analogous leucine variant (F2L) does not. Maintenance of the type II polyproline helix conformation is also important for EVH1 domain binding (84), but as with short ActA-derived peptides (72), single amino acid substitutions at residues Pro3, Pro4, and Pro6 lead only to small reductions in Mena $_{1-112}$ affinity, indicating that the secondary structure is not significantly perturbed.

Structural data from CD and AU is consistent with a model in which monomeric pGolemi adopts an aPP-like fold in the absence of the EVH1 domain. Substitution of alanine at pGolemi residue positions that are important for aPP folding (in variants P1A, P4A, P7A, L16A, F19A, L23A, Y26A, and, to a lesser extent, V29A) leads to significant decreases in the $\mathrm{MRE}_{222}$ signal by $\mathrm{CD}$, consistent with previous studies on DNA-binding miniature proteins (54). We note that the structure of pGolemi is also sensitive to the identity of amino acids substituted for Thr5, a position not previously identified as critical for miniature proteins folding. This observation suggests that the ActA residues grafted onto the aPP scaffold have resulted in differences in the packing of the miniature protein's hydrophobic core, which likely results in altered presentation of surface residues as well. Any effect the substitutions have on the aggregation state is not known.

\section{Residues throughout the pGolemi sequence contribute to EVH1 domain affinity}

Every pGolemi variant except P1A, T5L, and E9A exhibited decreased affinity for Mena $_{1-112}$. Among variants containing alanine in place of a residue derived from ActA, significant loss of binding was observed only upon alteration of Phe2, the key aromatic residue from the binding epitope, and Pro6, which is located centrally within the pGolemi sequence. Substitution of the remaining ActA-derived residues resulted in only minor losses in binding energy, consistent with the observations of others, suggesting that these residues serve a 
scaffolding role to maintain the epitope's secondary structure $(42,45,72)$. Analysis of the effects of altering aPP $\alpha$-helix-derived residues shows that three residues located centrally in the primary sequence, Ala11, Leu16 and Leu23, are important for binding. Leucine substitution for Ala11 does not significantly perturb $\alpha$-helix structure, but alanine substitution for either Leu 16 and Leu 23 causes a dramatic loss in $\alpha$-helical secondary structure, consistent with the role of these positions in packing the hydrophobic core of an aPP-like scaffold in this and other miniature proteins (54). By contrast, variants with substitutions for aPP-derived folding residues located near the termini of the pGolemi sequence, Pro1, Tyr26, and Val29, suffer small or negligible reductions in Mena $1-112$ binding in spite of the fact that they are relatively unstructured. Taken together with the observation that truncated peptides containing only the PPII helix portion do not bind to Mena ${ }_{1-112}$ (this work, (66)), these data support the notion that the C-terminal portion of the pGolemi sequence is critical to Mena ${ }_{1-112}$ affinity. The data leave open to question whether Ala11, Leu16, and Leu23 contribute to binding by direct contact or indirect conformational effects; however, additional data could provide the necessary insight into the separate or combined functions of these residues. In general, residue substitutions that most significantly diminished Mena ${ }_{1-112}$ also decreased the already moderate affinity for VASP $_{1-115}$; any negative impact on $\mathrm{Evl}_{1-115}$ binding could not be evaluated because of the low affinity of the $\mathrm{Evl}_{1-115} \bullet \mathrm{pGolemi}$ complex. Variants with improved affinity for both VASP $_{1-115}$ and $\mathrm{Evl}_{1-115}$ bore substitutions for aPP-derived PPII helix folding residues (Pro1 and Pro4), aPP-derived non-folding residues (Thr5, Ala11), and ActA-derived residues (Glu9 and Glu10; Pro3 for VASP $1-115$ only). Notably, F2L showed improved affinity for both VASP $_{1-115}$ and $\mathrm{Evl}_{1-115}$. Short peptide fragments of ActA studied by Ball and co-workers (46) show the opposite trend in VASP EVH1 binding for Phe versus Leu at the equivalent position, highlighting a difference between miniature protein and unfolded peptide ligands. The observation that small changes can improve affinity for $\mathrm{VASP}_{1-115}$ and $\mathrm{Evl}_{1-115}$ also points to the possibility of using phage display to evolve pGolemi into a second generation miniature protein with high affinity for these paralogs.

\section{Residues throughout the pGolemi sequence contribute to EVH1 paralog specificity}

Mutational analyses of ActA peptides and endogenous host cell Ena/VASP binding partners indicate that the $\mathrm{EVH} 1$ ligand is $(\mathrm{D} / \mathrm{E})(\mathrm{F} / \mathrm{L} / \mathrm{W} / \mathrm{Y}) \mathrm{PX} \phi \mathrm{PX}_{1-3}$ (abbreviated FP4), where $\mathrm{X}$ is any amino acid and $\phi$ is hydrophobic $(72,83)$. Short peptides containing this consensus derived from ActA bind EVH1 domain paralogs with similar affinities (46,72) (66). Ball and coworkers compared the binding of the EVH1 domains of Mena and VASP for 6-13 residue ActA peptide variants by fluorescence perturbation and found that the interaction with Mena $1-112$ was universally of higher affinity (46). Truncations at the termini as well as single amino acid substitutions decreased affinity for both Mena ${ }_{1-112}$ and VASP $1-115$. Niebuhr and co-workers used solid-phase binding studies to compare the relative binding of Mena and VASP to 10residue peptide ligands (72) and found that within the core consensus, certain substitutions, particularly at position 2 but also positions 3, 4, and 6 (pGolemi numbering), could lead to selectivity between Mena $1_{1-112}$ and $\mathrm{VASP}_{1-115}$. The pGolemi variants in our study all showed the general trend of higher affinity for Mena ${ }_{1-112}$ than for $\mathrm{VASP}_{1-115}$ (or $\mathrm{Evl}_{1-115}$ ), with the exception of A11L and T5A.

The effects of single amino acid changes in pGolemi on the striking EVH1 paralog binding specificity fall into two broad groups. Positions at which substitution results in significantly reduced binding to all three class I EVH1 domains include the key aromatic residue from the EVH1 binding epitope, Phe2, and the aPP-derived $\alpha$-helix folding residues, Leu16 and Leu23. Substitutions at the remaining residue positions show a spectrum of paralog specificity profiles resulting from modulated affinity towards $\mathrm{Mena}_{1-112}, \mathrm{VASP}_{1-115}$, and $\mathrm{Evl}_{1-115}$. In general, substitutions for ActA-derived residues (F2L, P3A and P3Z, P6A, E9A, E10A) had a mild negative effect on Mena ${ }_{1-112}$ affinity and a positive effect on affinity for VASP $\mathrm{V}_{1-115}$ and 
$\mathrm{Evl}_{1-115}$. P6A is an exception in that affinity is decreased for both $\mathrm{Mena}_{1-112}$ and VASP ${ }_{1-115}$ (the effect on $\mathrm{Evl}_{1-115}$ affinity is not known). One study of paralog-dependent effects of binding by short (10 residue) ActA-derived peptide variants showed that the F2L substitution (pGolemi numbering), for example, diminished affinity for VASP (72). In another study of ActA peptoids containing N-substituted residues at the Pro3 position, species with long, hydrophobic side chains bound to VASP, but those with short side chains, like sarcosine, did not (73). The epitope-derived residues are therefore important for determining paralog specificity, but the sequence context is relevant. aPP-derived residues also play a role in paralog specificity. Substitutions for folding residues in the PPII helix portion of the molecule generally did not affect (P1A) or slightly decreased (P4A, P4Z) affinity for Mena ${ }_{1-112}$, but conferred increased affinity for both $\mathrm{VASP}_{1-115}$ and $\mathrm{Evl}_{1-115}$. The global decrease in EVH1 affinity of variants with substitutions for two $\alpha$-helix folding residues (L16A, L23A) exemplifies the paralogindependent role of these residues in specificity; on the other hand, the Y26A substitution resulted in an enhanced version of pGolemi's paralog specificity profile, with only a slight decrease in $\mathrm{Mena}_{1-112}$ affinity but no detectable binding to either VASP ${ }_{1-115}$ or $\mathrm{Evl}_{1-115}$ up to at least $50 \mu \mathrm{M}$. Two additional aPP-derived residues, Thr5 and Ala11, were also implicated as major determinants of paralog specificity by modulating affinity to all three domains by increasing affinity for both $\mathrm{VASP}_{1-115}$ and $\mathrm{Evl}_{1-115}$ while slightly decreasing Mena $\mathrm{A}_{1-112}$ affinity. This data provides evidence that pGolemi residues outside the binding epitope have a spectrum of roles that subtly influence paralog specificity.

Overall, the analysis of pGolemi specificity provides a detailed map of the effects of residue substitutions on global EVH1 domain affinity as well as paralog specificity. The importance of the context of epitope presentation (i.e. unfolded peptide vs. miniature protein) in specificity is highlighted by the observation of sometimes contradictory effects of analogous substitutions across different studies of EVH1 domain-ligand interactions. This data collection will be invaluable in guiding the design of miniature protein libraries for the purpose of discovering molecules with desired interaction specificity profiles.

\section{Limited relationship between Mena, but not VASP or Evl, affinity and $\alpha$-helix secondary structure}

Co-crystal structures of the EVH1 domains of Mena and Evl in complex with short ActA peptide ligands show that the peptide adopts a type II polyproline helix secondary structure conformation $(42,45)$. $\alpha$-helical epitopes whose conformations are restricted because they are presented in the context of a miniature protein (54) pay a lower entropic cost upon binding to their cognate domains because they are prestructured. By contrast, short peptides ( $>10$ residues) containing sequences with a propensity towards forming type II polyproline helices can spontaneously adopt this conformation in aqueous solution (37). Our initial report of pGolemi design, structure, and function showed that the portion of the molecule derived from the $\alpha$ helix of aPP contributes at least $3.5 \mathrm{kcal} / \mathrm{mol}$ to Mena ${ }_{1-112}$ binding (66), raising the question of whether the $\alpha$-helix plays an analogous role in prestructuring or whether some other mechanism is involved. We investigated the premise that the aPP fold contributes to binding by plotting the intensity of the $\alpha$-helix signature $\left(\mathrm{MRE}_{222}\right)$ of the pGolemi variants against affinity for $\mathrm{Mena}_{1-112}, \mathrm{VASP}_{1-115}$, and $\mathrm{Evl}_{1-115}$ (Figure 7).

Examination of the data in Figure 7 suggests that in general, pGolemi variants possessing high levels of $\alpha$-helix secondary structure in the absence of bound EVH1 domain also possess the

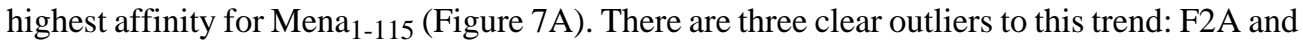
A11L, which are well folded but bind Mena ${ }_{1-115}$ with low affinity, and $\mathrm{P} 1 \mathrm{~A}$, which is poorly folded but binds Mena ${ }_{1-115}$ well. If, as argued above, pGolemi and Act $_{11}$ bind Mena $\mathrm{A}_{1-115}$ in a similar manner, then Phe2 is involved in direct contact with the domain, so low affinity of the F2A results from disruption of a key epitope residue and not from loss of structure. In the 
case of Ala11, substitution for leucine does not reduce folding; however, changing the identity of the side chain at this position results in modulated affinity for all three paralogs (this work). It can therefore tentatively be concluded that Ala11 also contacts the domain surface. In the case of P1A, given that the 11-residue truncated version of this variant does not bind Mena $_{1-112}$, the likely role of this residue is primarily in maintaining the folded structure rather than in direct domain contact. Since Mena $1-112$ binding is very sensitive to other substitutions that disrupt $\alpha$-helix structure, it may be that this particular variant can fold upon binding with the energetic cost being paid by the increased availability of ligand conformations that are highly favorable to Mena $1_{1-112}$ binding. Alternatively, P1A might remain unfolded even after binding, the high affinity arising from the fact that more of the hydrophobic area of the molecule is exposed, thus allowing non-specific interactions to form following the initial recruitment effected by the FP4 core. Overall, the data support the claim that the presentation of the EVH1 domain binding epitope in the context of an aPP scaffold results in improved affinity for Mena $_{1-112}$ through stabilization of the tertiary structure, which in turn emerges from the synergistic interactions of the $\alpha$ - and PPII helices. In contrast to the relationship for Mena $_{1-112}$ between structure and binding, no such relationship exists for either VASP 1-115 $_{\text {or }}$ $\mathrm{Evl}_{1-115}$. This suggests that, as was seen with in vitro evolution of p007 (53), maintaining or restoring structure will be an important consideration during future efforts to generate high affinity miniature proteins for the other EVH1 paralogs. Plots of the $\alpha$-helicity of pGolemi variants and their specificity reveal no correlation.

\section{Direct relationship between affinity and specificity}

The data suggest that there exists a direct relationship between the affinity of a pGolemi variant for Mena $\mathrm{1}_{115}$ and its ability to discriminate Mena $\mathrm{1}_{112}$ from the other EVH1 paralogs (Figure 8). Such a relationship has also been observed for the miniature protein p007, which binds DNA with high affinity and specificity, as well as in a wide range of other systems, ranging from selective binding of $\mathrm{Na}^{+}$versus $\mathrm{K}^{+}$(85), to affinity-matured antibodies (86) to RNA aptamers (87). The laws of thermodynamics do not explicitly supply a connection between $\delta \mathrm{G}_{\mathrm{Mena}}$ and $\delta \mathrm{G}_{\mathrm{Spec}}$; however, in all these cases, the relationship has been rationalized on the basis of ligand preorganization. This relationship also leads to the conclusion that by presenting a naturally-evolved epitope fragment that binds with relatively high affinity to a protein domain in the context of a well-folded scaffold, a new dimension of specificity can be added to the ligand's functional characteristics.

\section{Aberrant motility of Listeria is correlated with EVH1 paralog specificity}

The use of peptides to perturb protein-protein interactions is an established approach that has been used to provide important insights into the mechanisms of cytoskeleton control, and the motility of L. monocytogenes in particular. In 1994, Southwick and co-workers reported that microinjecting an $\mathrm{FP}_{4}$-containing peptide into PtK2 cells infected with $L$. monocytogenes blocked tail elongation and halted motility, but microinjection of poly-L-proline led to increased tail length and bacterial speed (70). Niebuhr and co-workers' engineered $L$. monocytogenes to lack the EVH1 domain binding site of ActA and demonstrated that the bacteria could still accumulate actin at their surfaces but at a reduced level (72). Actin was eventually able to polarize and form a stubby tail, which allowed motility to proceed at a dramatically reduced speed. Our observation that pGolemi binds EVH1 domains in a similar manner to ActA peptides and also causes a decrease in median speed of L. monocytogenes is therefore in agreement with the work of others in that EVH1•ActA interactions are required to maintain speed.

Discontinous actin tails have been observed in previous studies of L. monocytogenes motility at steady state using a variety of systems, including cell culture infection and cell extracts $(61,62)$, as well as in the context of ActA covered beads where motility was reconstituted using 
purified proteins (63). The first example was described by Lasa et al. as a result of the deletion of residues 21-97 of ActA, the site of interaction with the actin branching and nucleating Arp2/3 complex (61). Lauer et al. observed this phenotype in an alanine scanning of the charged residues of the ActA protein in the region that spanned from 165-260, which is outside the polyproline rich repeat region (63-390)(62). In (63), discontinuous tails were seen while monitoring the motility of ActA-coated beads in the absence of VASP in a reconstituted motility medium. Our results corroborate the last two studies, implicating the EVH1•ActA interaction in this phenotype. More recently, a study of the process of initiation of Listeria motility showed that "hopping" is in fact a characteristic step in the transition between polarized actin cloud formation and the establishment of tails that can maintain persistent speed and direction (64). Actin accumulates at one of the poles and bacteria start to move forward with a sudden burst of speed that breaks the link with the tail. Bacteria come to a complete stop upon collision with a physical obstruction in the medium, and the process repeats until a long, weak tail develops that eventually matures into a robust tail capable of maintaining persistent speed and directionality. In that study, disruption of the EVH1 binding site by mutating the key Phe in the binding epitope of ActA showed a similar effect to treatment of wild type $L$. monocytogenes with pGolemi in that erratic hopping motility persisted and tails did not follow through the maturation process. In all the cases of discontinuous tails, an imbalance between the propulsive and retarding forces is likely responsible for trapping the bacteria or bead in an intermediate stage of tail development. For the cases where Ena/VASP•ActA interactions are implicated, the imbalance may be due to bursts of propulsion by rapid actin polymerization partially overwhelming the weakened molecular connection between the tail and the bacteria or bead. The clear correlation between the effect of pGolemi on L. monocytogenes motility and the miniature protein's in vitro properties as a paralog-specific inhibitor of protein-protein interactions taken together with the fact that hopping motility is a stage in the tail maturation process suggests that the different Ena/VASP paralogs may not play equivalent roles in the transition from the initiation phase to robust motility. Future work will explore this hypothesis further.

\section{Supplementary Material}

Refer to Web version on PubMed Central for supplementary material.

\section{ACKNOWLEDGEMENT}

We thank James Lear and Abby Maranda for assistance with analytical ultracentrifugation and Julie Theriot for assistance with analyzing $L$. monocytogenes motility data.

\section{ABBREVIATIONS}

PPII helix, type II polyproline helix; aPP, avian pancreatic polypeptide; $\mathrm{CD}$, circular dichroism; $K_{\mathrm{d}}$, dissociation constant; EVH1, Ena/VASP homology domain 1; $\mathrm{MRE}_{222}$, mean residue ellipticity at $222 \mathrm{~nm}$.

\section{REFERENCES}

1. Tanoue T, Takeichi M. New insights into Fat cadherins. J Cell Sci 2005;118:2347-2353. [PubMed: 15923647]

2. Sechi AS, Wehland J. ENA/VASP proteins: multifunctional regulators of actin cytoskeleton dynamics. Front Biosci 2004;9:1294-1310. [PubMed: 14977545]

3. Krause M, Dent EW, Bear JE, Loureiro JJ, Gertler FB. Ena/VASP proteins: regulators of the actin cytoskeleton and cell migration. Annu Rev Cell Dev Biol 2003;19:541-564. [PubMed: 14570581]

4. Kwiatkowski AV, Gertler FB, Loureiro JJ. Function and regulation of Ena/VASP proteins. Trends Cell Biol 2003;13:386-392. [PubMed: 12837609] 
5. Renfranz PJ, Beckerle MC. Doing (F/L)PPPPs: EVH1 domains and their proline-rich partners in cell polarity and migration. Curr Opin Cell Biol 2002;14:88-103. [PubMed: 11792550]

6. Bear JE, Krause M, Gertler FB. Regulating cellular actin assembly. Curr Opin Cell Biol 2001;13:158166. [PubMed: 11248549]

7. Meyer G, Feldman EL. Signaling mechanisms that regulate actin-based motility processes in the nervous system. J Neurochem 2002;83:490-503. [PubMed: 12390511]

8. Koleske AJ. Do filopodia enable the growth cone to find its way? Sci STKE 2003;2003:pe20. [PubMed: 12759482]

9. Haffner C, Jarchau T, Reinhard M, Hoppe J, Lohmann SM, Walter U. Molecular-Cloning, StructuralAnalysis and Functional Expression of the Proline-Rich Focal Adhesion and MicrofilamentAssociated Protein Vasp. EMBO J 1995;14:19-27. [PubMed: 7828592]

10. Gertler FB, Doctor JS, Hoffmann FM. Genetic Suppression of Mutations in the Drosophila Abl Protooncogene Homolog. Science 1990;248:857-860. [PubMed: 2188361]

11. Gertler FB, Niebuhr K, Reinhard M, Wehland J, Soriano P. Mena, a relative of VASP and Drosophila enabled, is implicated in the control of microfilament dynamics. Cell 1996;87:227-239. [PubMed: 8861907]

12. Halbrugge M, Walter U. Purification of a vasodilator-regulated phosphoprotein from human platelets. Eur J Biochem 1989;185:41-50. [PubMed: 2806262]

13. Ball LJ, Jarchau T, Oschkinat H, Walter U. EVH 1 domains: structure, function and interactions. FEBS Letters 2002;513:45-52. [PubMed: 11911879]

14. Harbeck B, Huttelmaier S, Schluter K, Jockusch BM, Illenberger S. Phosphorylation of the vasodilator-stimulated phosphoprotein regulates its interaction with actin. J Biol Chem 2000;275:30817-30825. [PubMed: 10882740]

15. Eigenthaler M, Nolte C, Halbrugge M, Walter U. Concentration and regulation of cyclic nucleotides, cyclic-nucleotide-dependent protein kinases and one of their major substrates in human platelets. Estimating the rate of cAMP-regulated and cGMP-regulated protein phosphorylation in intact cells. Eur J Biochem 1992;205:471-481. [PubMed: 1315268]

16. Butt E, Abel K, Krieger M, Palm D, Hoppe V, Hoppe J, Walter U. cAMP- and cGMP-dependent protein kinase phosphorylation sites of the focal adhesion vasodilator-stimulated phosphoprotein (VASP) in vitro and in intact human platelets. J Biol Chem 1994;269:14509-14517. [PubMed: 8182057]

17. Chitaley K, Chen L, Galler A, Walter U, Daum G, Clowes AW. Vasodilator-stimulated phosphoprotein is a substrate for protein kinase C. FEBS Lett 2004;556:211-215. [PubMed: 14706852]

18. Krugmann S, Jordens I, Gevaert K, Driessens M, Vandekerckhove J, Hall A. Cdc42 induces filopodia by promoting the formation of an IRSp53 : Mena complex. Curr Biol 2001;11:1645-1655. [PubMed: 11696321]

19. Ahern-Djamali SM, Bachmann C, Hua P, Reddy SK, Kastenmeier AS, Walter U, Hoffmann FM. Identification of profilin and src homology 3 domains as binding partners for Drosophila enabled. Proc Natl Acad Sci U S A 1999;96:4977-4982. [PubMed: 10220404]

20. Russo T, Faraonio R, Minopoli G, De Candia P, De Renzis S, Zambrano N. Fe65 and the protein network centered around the cytosolic domain of the Alzheimer's beta-amyloid precursor protein. FEBS Lett 1998;434:1-7. [PubMed: 9738440]

21. Reinhard M, Giehl K, Abel K, Haffner C, Jarchau T, Hoppe V, Jockusch BM, Walter U. The prolinerich focal adhesion and microfilament protein VASP is a ligand for profilins. EMBO J 1995;14:15831589. [PubMed: 7737110]

22. Zimmermann J, Labudde D, Jarchau T, Walter U, Oschkinat H, Ball LJ. Relaxation, equilibrium oligomerization, and molecular symmetry of the VASP (336-380) EVH2 tetramer. Biochemistry 2002;41:11143-11151. [PubMed: 12220179]

23. Tani K, Sato S, Sukezane T, Kojima H, Hirose H, Hanafusa H, Shishido T. Abl interactor 1 promotes tyrosine 296 phosphorylation of mammalian enabled (Mena) by c-Abl kinase. J Biol Chem 2003;278:21685-21692. [PubMed: 12672821] 
24. Walders-Harbeck B, Khaitlina SY, Hinssen H, Jockusch BM, Illenberger S. The vasodilatorstimulated phosphoprotein promotes actin polymerisation through direct binding to monomeric actin. FEBS Lett 2002;529:275-280. [PubMed: 12372613]

25. Bachmann C, Fischer L, Walter U, Reinhard M. The EVH2 domain of the vasodilator-stimulated phosphoprotein mediates tetramerization, F-actin binding, and actin bundle formation. J Biol Chem 1999;274:23549-23557. [PubMed: 10438535]

26. Kuhnel K, Jarchau T, Wolf E, Schlichting I, Walter U, Wittinghofer A, Strelkov SV. The VASP tetramerization domain is a right-handed coiled coil based on a 15-residue repeat. Proc Natl Acad Sci U S A 2004;101:17027-17032. [PubMed: 15569942]

27. Sparks AB, Rider JE, Hoffman NG, Fowlkes DM, Quillam LA, Kay BK. Distinct ligand preferences of Src homology 3 domains from Src, Yes, Abl, Cortactin, p53bp2, PLCgamma, Crk, and Grb2. Proc Natl Acad Sci U S A 1996;93:1540-1544. [PubMed: 8643668]

28. Yu H, Chen JK, Feng S, Dalgarno DC, Brauer AW, Schreiber SL. Structural basis for the binding of proline-rich peptides to SH3 domains. Cell 1994;76:933-945. [PubMed: 7510218]

29. Macias MJ, Wiesner S, Sudol M. WW and SH3 domains, two different scaffolds to recognize prolinerich ligands. FEBS Letters 2002;513:30-37. [PubMed: 11911877]

30. Chen HI, Sudol M. The WW domain of Yes-associated protein binds a proline-rich ligand that differs from the consensus established for Src homology 3-binding modules. Proc Natl Acad Sci U S A 1995;92:7819-7823. [PubMed: 7644498]

31. Macias MJ, Hyvonen M, Baraldi E, Schultz J, Sudol M, Saraste M, Oschkinat H. Structure of the WW domain of a kinase-associated protein complexed with a proline-rich peptide. Nature 1996;382:646-649. [PubMed: 8757138]

32. Nishizawa K, Freund C, Li J, Wagner G, Reinherz EL. Identification of a proline-binding motif regulating CD2-triggered T lymphocyte activation. Proc Natl Acad Sci U S A 1998;95:14897-14902. [PubMed: 9843987]

33. Freund C, Dotsch V, Nishizawa K, Reinherz EL, Wagner G. The GYF domain is a novel structural fold that is involved in lymphoid signaling through proline-rich sequences. Nat Struct Biol 1999;6:656-660. [PubMed: 10404223]

34. Pornillos O, Alam SL, Davis DR, Sundquist WI. Structure of the Tsg101 UEV domain in complex with the PTAP motif of the HIV-1 p6 protein. Nat Struct Biol 2002;9:812-817. [PubMed: 12379843]

35. Pornillos O, Alam SL, Rich RL, Myszka DG, Davis DR, Sundquist WI. Structure and functional interactions of the Tsg101 UEV domain. EMBO J 2002;21:2397-2406. [PubMed: 12006492]

36. Schutt CE, Myslik JC, Rozycki MD, Goonesekere NC, Lindberg U. The structure of crystalline profilin-beta-actin. Nature 1993;365:810-816. [PubMed: 8413665]

37. Mahoney NM, Janmey PA, Almo SC. Structure of the profilin-poly-L-proline complex involved in morphogenesis and cytoskeletal regulation. Nat Struct Biol 1997;4:953-960. [PubMed: 9360613]

38. Mahoney NM, Rozwarski DA, Fedorov E, Fedorov AA, Almo SC. Profilin binds proline-rich ligands in two distinct amide backbone orientations. Nat Struct Biol 1999;6:666-671. [PubMed: 10404225]

39. Zarrinpar A, Bhattacharyya RP, Lim WA. The Structure and Function of Proline Recognition Domains. Sci STKE 2003;2003:re8. [PubMed: 12709533]

40. Ball LJ, Kuhne R, Schneider-Mergener J, Oschkinat H. Recognition of Proline-Rich Motifs by Protein-Protein-Interaction Domains. Angew Chem Int Ed Engl 2005;44:2852-2869. [PubMed: 15880548]

41. Volkman BF, Prehoda KE, Scott JA, Peterson FC, Lim WA. Structure of the N-WASP EVH1 domainWIP complex: Insight into the molecular basis of Wiskott-Aldrich Syndrome. Cell 2002;111:565576. [PubMed: 12437929]

42. Prehoda KE, Lee DJ, Lim WA. Structure of the Enabled/VASP homology 1 domain-peptide complex: A Key Component in the spatial control of actin assembly. Cell 1999;97:471-480. [PubMed: 10338211]

43. Harmer NJ, Sivak JM, Amaya E, Blundell TL. 1.15 angstrom Crystal structure of the X-tropicalis Spred1 EVH1 domain suggests a fourth distinct peptide-binding mechanism within the EVH1 family. FEBS Letters 2005;579:1161-1166. [PubMed: 15710406] 
44. Beneken J, Tu JC, Xiao B, Nuriya M, Yuan JP, Worley PF, Leahy DJ. Structure of the Homer EVH1 domain-peptide complex reveals a new twist in polyproline recognition. Neuron 2000;26:143-154. [PubMed: 10798399]

45. Fedorov AA, Fedorov E, Gertler F, Almo SC. Structure of EVH1, a novel proline-rich ligand-binding module involved in cytoskeletal dynamics and neural function. Nat Struct Biol 1999;6:661-665. [PubMed: 10404224]

46. Ball LJ, Kuhne R, Hoffmann B, Hafner A, Schmieder P, Volkmer-Engert R, Hof M, Wahl M, Schneider-Mergener J, Walter U, Oschkinat H, Jarchau T. Dual epitope recognition by the VASP EVH1 domain modulates polyproline ligand specificity and binding affinity. EMBO Journal 2000;19:4903-4914. [PubMed: 10990454]

47. Rutledge S, Chin J, Schepartz A. A View to a Kill: Ligands for Bcl-2 family proteins. Curr. Opin. Chem. Biol 2002;6:479-485. [PubMed: 12133724]

48. Gemperli AC, Rutledge SE, Maranda A, Schepartz A. Paralog-selective ligands for Bcl-2 proteins. J Am Chem Soc 2005;127:1596-1597. [PubMed: 15700967]

49. Rutledge SE, Volkman HM, Schepartz A. Molecular recognition of protein surfaces: High affinity ligands for the CBPKIX domain. J Am Chem Soc 2003;125:14336-14347. [PubMed: 14624582]

50. Volkman HM, Rutledge SE, Schepartz A. Binding mode and transcriptional activation potential of high affinity ligands for the CBPKIX domain. J Am Chem Soc 2005;127:4649-4658. [PubMed: 15796530]

51. Kritzer JA, Zutshi R, Cheah M, Ran FA, Webman R, Wongjirad TM, Schepartz A. Miniature protein inhibitors of the p53-hDM2 interaction. Chembiochem 2006;7:29-31. [PubMed: 16397877]

52. Chin JW, Schepartz A. Design and Evolution of a Miniature Bcl-2 Binding Protein. Angew Chem Int Ed Engl 2001;40:3806-3809. [PubMed: 11668539]

53. Chin JW, Schepartz A. Concerted evolution of structure and function in a miniature protein. J Am Chem Soc 2001;123:2929-2930. [PubMed: 11456999]

54. Yang L, Schepartz A. Relationship between folding and function in a sequence-specific miniature DNA-binding protein. Biochemistry 2005;44:7469-7478. [PubMed: 15895990]

55. Montclare JK, Schepartz A. Miniature homeodomains: high specificity without an N-terminal arm. J Am Chem Soc 2003;125:3416-3417. [PubMed: 12643688]

56. Schneider TL, Mathew RS, Rice KP, Tamaki K, Wood JL, Schepartz A. Increasing the kinase specificity of k252a by protein surface recognition. Org Lett 2005;7:1695-1698. [PubMed: 15844883]

57. Cobos ES, Pisabarro MT, Vega MC, Lacroix E, Serrano L, Ruiz-Sanz J, Martinez JC. A miniprotein scaffold used to assemble the polyproline II binding epitope recognized by SH3 domains. J Mol Biol 2004;342:355-365. [PubMed: 15313630]

58. Weston CJ, Cureton CH, Calvert MJ, Smart OS, Allemann RK. A stable miniature protein with oxaloacetate decarboxylase activity. Chembiochem 2004;5:1075-1080. [PubMed: 15300830]

59. Nicoll AJ, Allemann RK. Nucleophilic and general acid catalysis at physiological pH by a designed miniature esterase. Org Biomol Chem 2004;2:2175-2180. [PubMed: 15280952]

60. Guerrero L, Smart OS, Woolley GA, Allemann RK. Photocontrol of DNA binding specificity of a miniature engrailed homeodomain. J Am Chem Soc 2005;127:15624-15629. [PubMed: 16262429]

61. Lasa I, Gouin E, Goethals M, Vancompernolle K, David V, Vandekerckhove J, Cossart P. Identification of two regions in the N-terminal domain of ActA involved in the actin comet tail formation by Listeria monocytogenes. EMBO J 1997;16:1531-1540. [PubMed: 9130698]

62. Lauer P, Theriot JA, Skoble J, Welch MD, Portnoy DA. Systematic mutational analysis of the aminoterminal domain of the Listeria monocytogenes ActA protein reveals novel functions in actin-based motility. Mol Microbiol 2001;42:1163-1177. [PubMed: 11886549]

63. Samarin S, Romero S, Kocks C, Didry D, Pantaloni D, Carlier MF. How VASP enhances actin-based motility. J Cell Biol 2003;163:131-142. [PubMed: 14557252]

64. Rafelski SM, Theriot JA. Bacterial shape and ActA distribution affect initiation of Listeria monocytogenes actin-based motility. Biophys J 2005;89:2146-2158. [PubMed: 15980176]

65. Golemi-Kotra D, Mahaffy R, Footer MJ, Holtzman JH, Pollard TD, Theriot JA, Schepartz A. High affinity, paralog-specific recognition of the Mena EVH1 domain by a miniature protein. J Am Chem Soc 2004;126:4-5. [PubMed: 14709031] 
66. Theriot JA, Fung DC. Listeria monocytogenes-based assays for actin assembly factors. Meth Enz 1998;298:114-122.

67. Nguyen JT, Porter M, Amoui M, Miller WT, Zuckermann RN, Lim WA. Improving SH3 domain ligand selectivity using a non-natural scaffold. Chem Biol 2000;7:463-473. [PubMed: 10903934]

68. Theriot JA, Rosenblatt J, Portnoy DA, Goldschmidt-Clermont PJ, Mitchison TJ. Involvement of profilin in the actin-based motility of L. monocytogenes in cells and in cell-free extracts. Cell 1994;76:505-517. [PubMed: 8313471]

69. Southwick FS, Purich DL. Arrest of Listeria movement in host cells by a bacterial ActA analogue: implications for actin-based motility. Proc Natl Acad Sci U S A 1994;91:5168-5172. [PubMed: 8197202]

70. Smith GA, Theriot JA, Portnoy DA. The tandem repeat domain in the Listeria monocytogenes ActA protein controls the rate of actin-based motility, the percentage of moving bacteria, and the localization of vasodilator-stimulated phosphoprotein and profilin. J Cell Biol 1996;135:647-660. [PubMed: 8909540]

71. Niebuhr K, Ebel F, Frank R, Reinhard M, Domann E, Carl UD, Walter U, Gertler FB, Wehland J, Chakraborty T. Novel proline-rich motif present in ActA of Listeria monocytogenes and cytoskeletal proteins is the ligand for the EVH1 domain, a protein module present in the Ena/VASP family. EMBO Journal 1997;16:5433-5444. [PubMed: 9312002]

72. Zimmermann J, Kuhne R, Volkmer-Engert R, Jarchau T, Walter U, Oschkinat H, Ball LJ. Design of N-substituted peptomer ligands for EVH1 domains. J Biol Chem 2003;278:36810-36818. [PubMed: 12857736]

73. Laurent V, Loisel TP, Harbeck B, Wehman A, Grobe L, Jockusch BM, Wehland J, Gertler FB, Carlier MF. Role of proteins of the Ena/VASP family in actin-based motility of Listeria monocytogenes. J Cell Biol 1999;144:1245-1258. [PubMed: 10087267]

74. Kocks C, Gouin E, Tabouret M, Berche P, Ohayon H, Cossart P. L. monocytogenes-induced actin assembly requires the actA gene product, a surface protein. Cell 1992;68:521-531. [PubMed: 1739966]

75. Pistor S, Chakraborty T, Walter U, Wehland J. The bacterial actin nucleator protein ActA of Listeria monocytogenes contains multiple binding sites for host microfilament proteins. Curr Biol 1995;5:517-525. [PubMed: 7583101]

76. Smith GA, Portnoy DA, Theriot JA. Asymmetric distribution of the Listeria monocytogenes ActA protein is required and sufficient to direct actin-based motility. Mol Microbiol 1995;17:945-951. [PubMed: 8596443]

77. Machner MP, Urbanke C, Barzik M, Otten S, Sechi AS, Wehland J, Heinz DW. ActA from Listeria monocytogenes can interact with up to four Ena/VASP homology 1 domains simultaneously. J Biol Chem 2001;276:40096-40103. [PubMed: 11489888]

78. Auerbuch V, Loureiro JJ, Gertler FB, Theriot JA, Portnoy DA. Ena/VASP proteins contribute to Listeria monocytogenes pathogenesis by controlling temporal and spatial persistence of bacterial actin-based motility. Mol Microbiol 2003;49:1361-1375. [PubMed: 12940993]

79. Bear JE, Loureiro JJ, Libova I, Fassler R, Wehland J, Gertler FB. Negative regulation of fibroblast motility by Ena/VASP proteins. Cell 2000;101:717-728. [PubMed: 10892743]

80. Jenzora A, Behrendt B, Small JV, Wehland J, Stradal TE. PREL1 provides a link from Ras signalling to the actin cytoskeleton via Ena/VASP proteins. FEBS Lett 2005;579:455-463. [PubMed: 15642358]

81. Lafuente EM, van Puijenbroek AA, Krause M, Carman CV, Freeman GJ, Berezovskaya A, Constantine E, Springer TA, Gertler FB, Boussiotis VA. RIAM, an Ena/VASP and Profilin ligand, interacts with Rap1-GTP and mediates Rap1-induced adhesion. Dev Cell 2004;7:585-595. [PubMed: 15469846]

82. Krause M, Leslie JD, Stewart M, Lafuente EM, Valderrama F, Jagannathan R, Strasser GA, Rubinson DA, Liu H, Way M, Yaffe MB, Boussiotis VA, Gertler FB. Lamellipodin, an Ena/VASP ligand, is implicated in the regulation of lamellipodial dynamics. Dev Cell 2004;7:571-583. [PubMed: 15469845] 
83. Geese M, Loureiro JJ, Bear JE, Wehland J, Gertler FB, Sechi AS. Contribution of Ena/VASP proteins to intracellular motility of listeria requires phosphorylation and proline-rich core but not F-actin binding or multimerization. Mol Biol Cell 2002;13:2383-2396. [PubMed: 12134077]

84. Hunke C, Hirsch T, Eichler J. Structure-Based Synthetic Mimicry of Discontinuous Protein Binding Sites: Inhibitors of the Interaction of Mena EVH1 Domain with Proline-Rich Ligands. Chembiochem 2006:1258-1264. [PubMed: 16810654]

85. Cram DJ. The design of molecular hosts, guests, and their complexes. Science 1988;240:760-767. [PubMed: 3283937]

86. Wedemayer GJ, Patten PA, Wang LH, Schultz PG, Stevens RC. Structural insights into the evolution of an antibody combining site. Science 1997;276:1665-1669. [PubMed: 9180069]

87. Eaton BE, Gold L, Zichi DA. Let's get specific: the relationship between specificity and affinity. Chem Biol 1995;2:633-638. [PubMed: 9383468] 

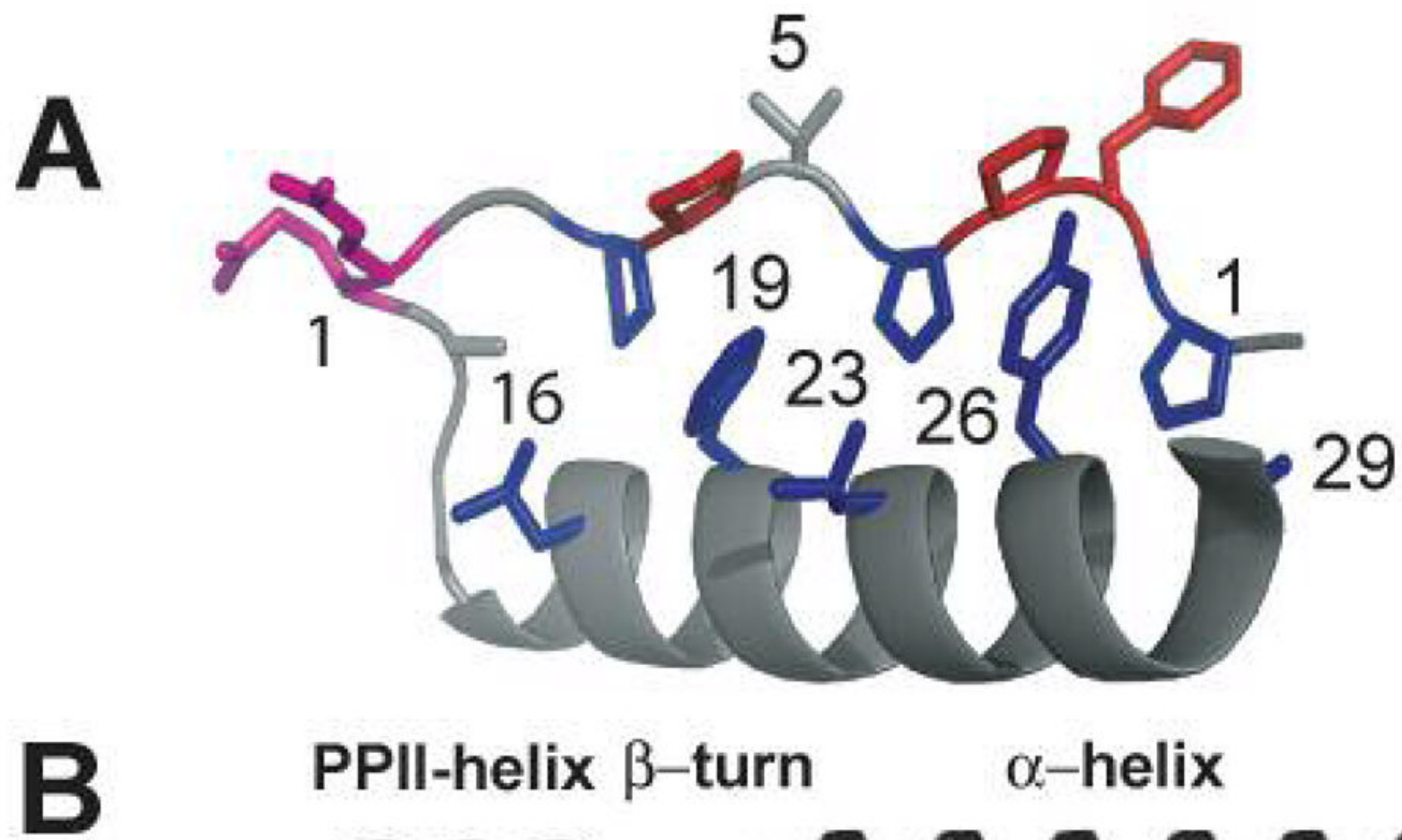

$\alpha-$ helix

aPP

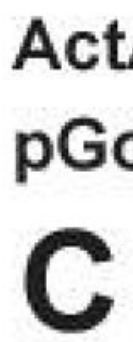

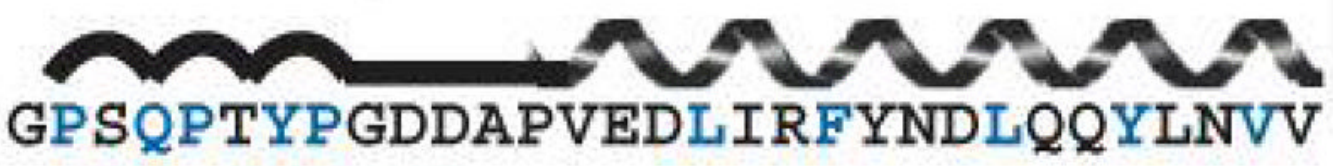

DFPPPPTDEEL

PFPPTPPGEEAPVEDLIRFYNDLQQYLNVV 10 20

Figure 1.

pGolemi variants and controls studied in this work. (A) Model of pGolemi structure obtained by substituting residues on aPP (PDB code: $1 \mathrm{ppt}$ ). Shown in lines are the side chains of the residues that were changed to produce variant molecules. Residues in blue contribute to the aPP hydrophobic core, while those in red or magenta are derived from the sequence of Act $_{11}$. The image was rendered in PyMol (Delano Scientific). (B) Sequence alignment of aPP and Act $_{11}$ (proline-rich repeat 1, residues 264-274) used to design pGolemi (GolemiKotra et al., 2004). A schematic representation of the aPP secondary structure is shown above the corresponding primary sequence. Color coding is as described in (A). (C) Sequence 
alignment of aPP and $\mathrm{Act}_{11}$ (proline-rich repeat 2, residues 299-309) used to design pGolemi-2. 

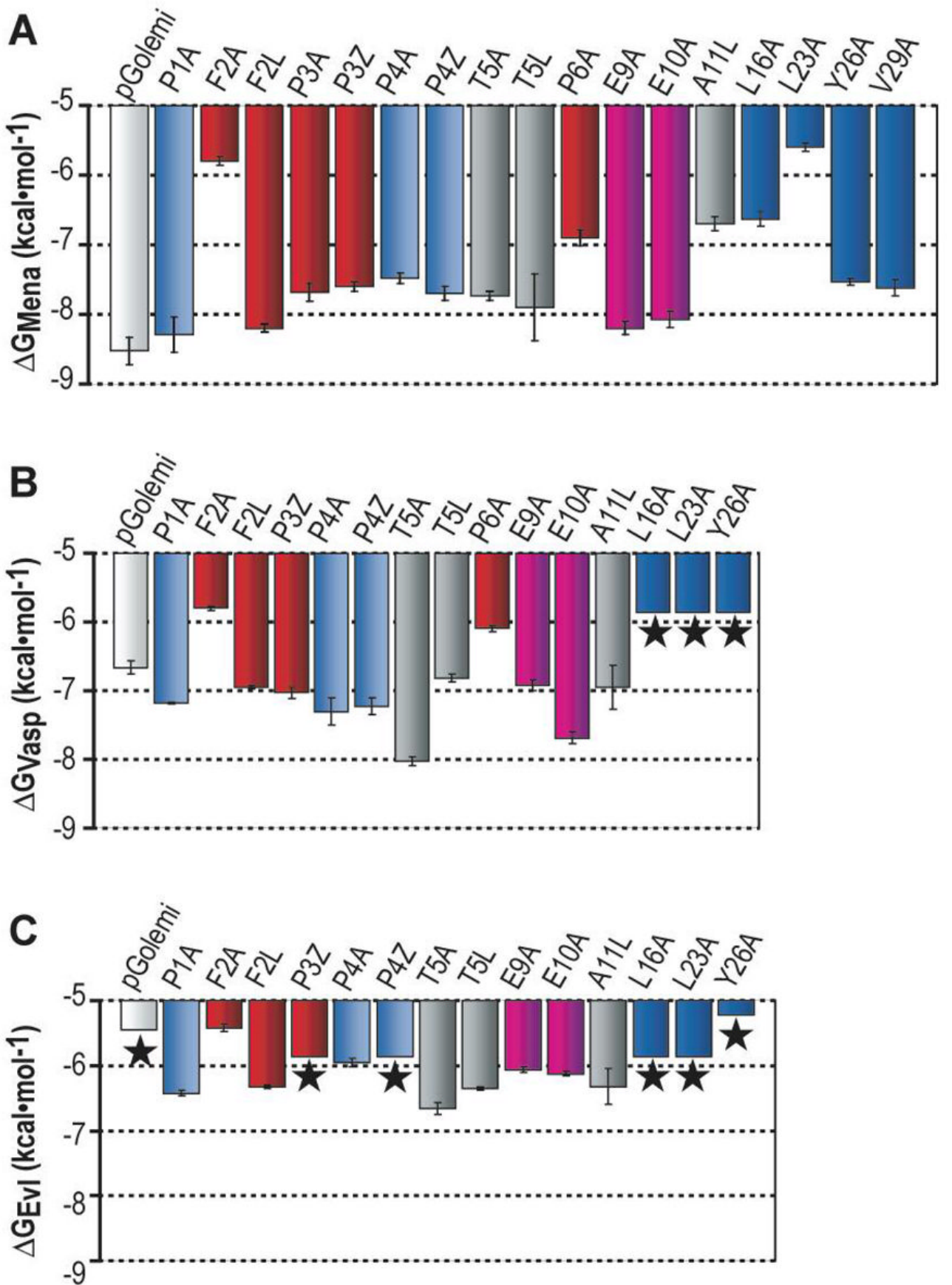

Figure 2.

Histogram representing the relative affinities of pGolemi variants for (A) Mena $1-112$, (B) VASP $_{1-115}$ or (C) Evl $_{1-115}$ Colors are described in Figure 1. Values of free energy were calculated from the relationship $\Delta \mathrm{G}=-\mathrm{RT} \ln K_{\mathrm{d}}$. Stars denote complexes whose affinities could only be estimated. We note that in the case of two pGolemi variants, P7A and F19A, the increase in EVH1 domain fluorescence expected with increasing ligand did not resemble the expected sigmoidal curve, possibly due to ligand aggregation. 

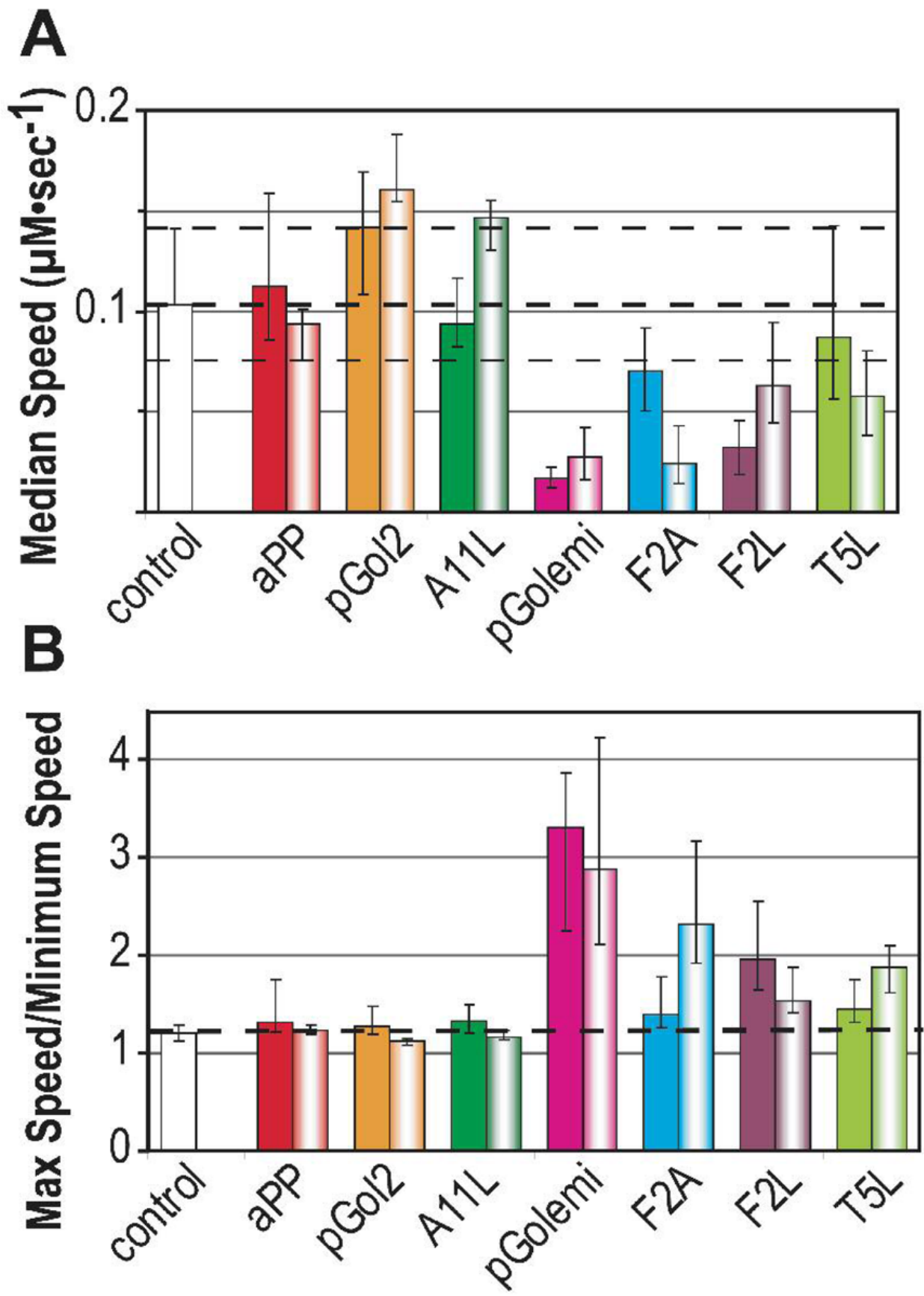

Figure 3.

(A) Plot of median speed $\left(\mu \mathrm{m} \bullet \mathrm{sec}^{-1}\right)$ of L. monocytogenes in the absence (white) or presence of the indicated ligand at $10 \mu \mathrm{M}$ (dark) and $100 \mu \mathrm{M}$ (light). Error bars represent the $25^{\text {th }}(-)$ and $75^{\text {th }}(+)$ percentile of moving bacteria. The number of bacteria analyzed at $10 \mu \mathrm{M}$ and 100 $\mu \mathrm{M}$, respectively, for each miniature protein were: 46 and 9 (aPP); 39 and 7 (pGol2); 33 and 21 (A11L); 15 and 27 (pGolemi); 62 and 41 (F2A); 38 and 28 (F2L); 59 and 23 (T5L); 68 (control in the absence of miniature protein). 

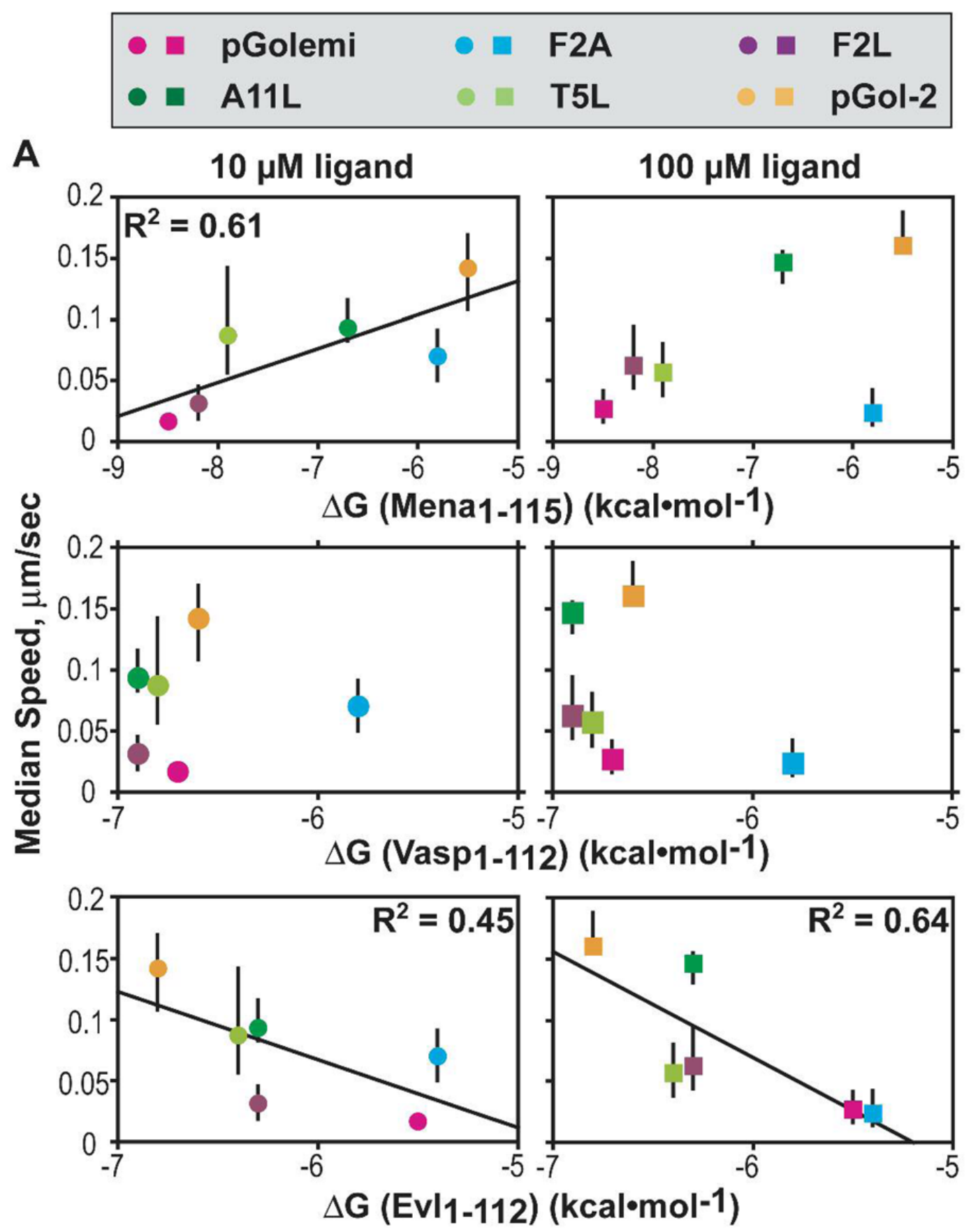

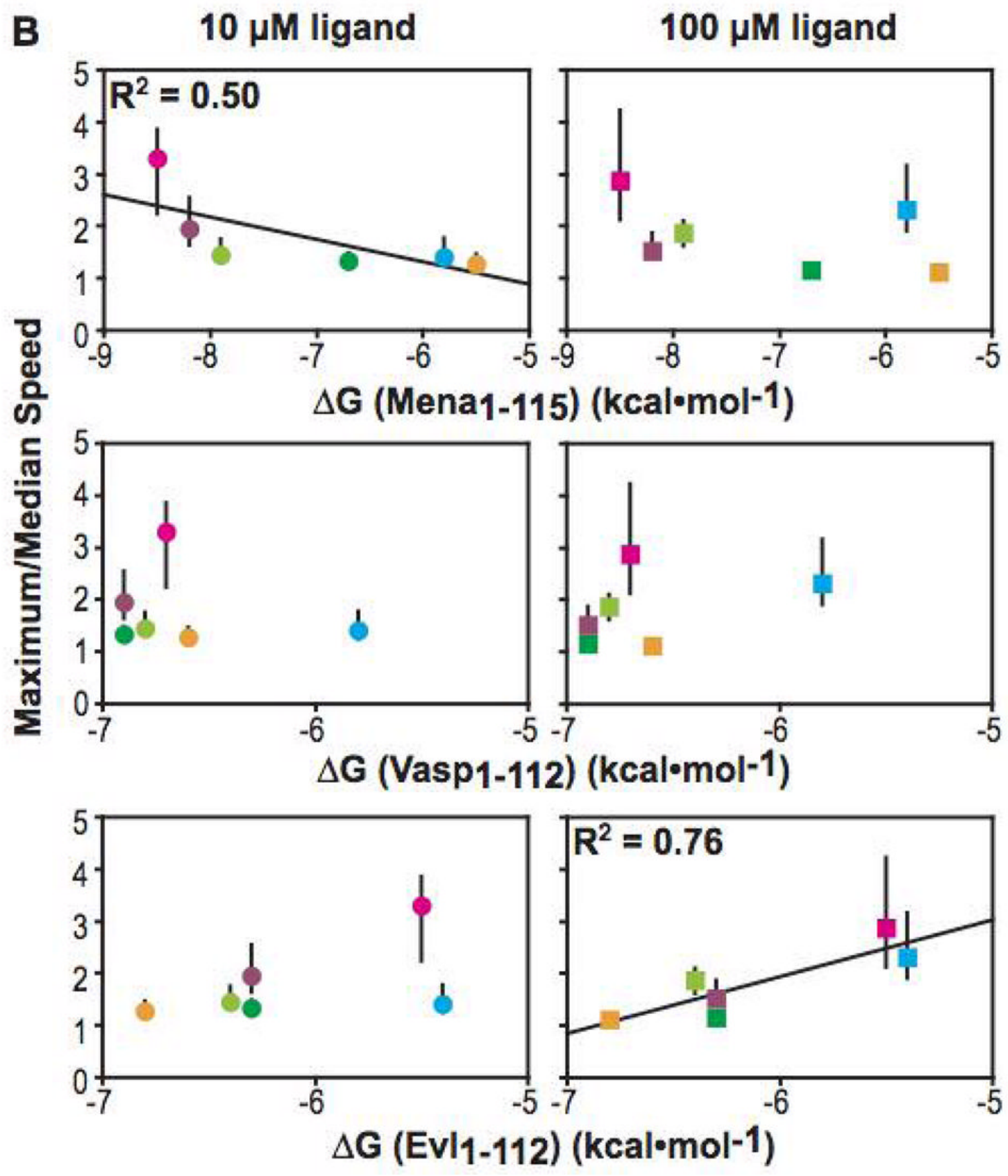

Figure 4.

Quantitative analysis of L. monocytogenes motility as a function of EVH1 domain affinity. Plots of (A) median speed and (B) the ratio of the maximum to median speed in the presence of 10 or $100 \mu \mathrm{M}$ miniature protein as a function of EVH1 domain affinity. Error bars represent the $25^{\text {th }}(-)$ and $75^{\text {th }}(+)$ percentile of moving bacteria. 


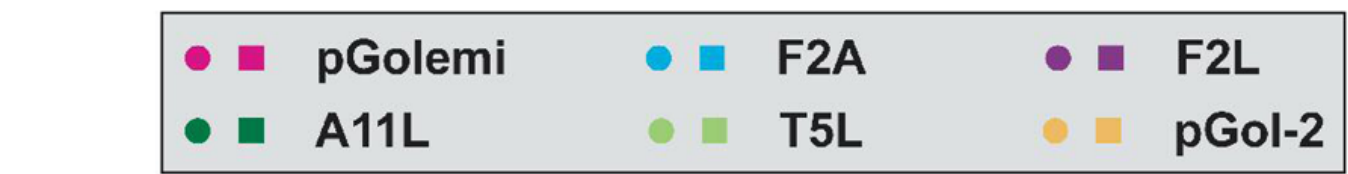

A
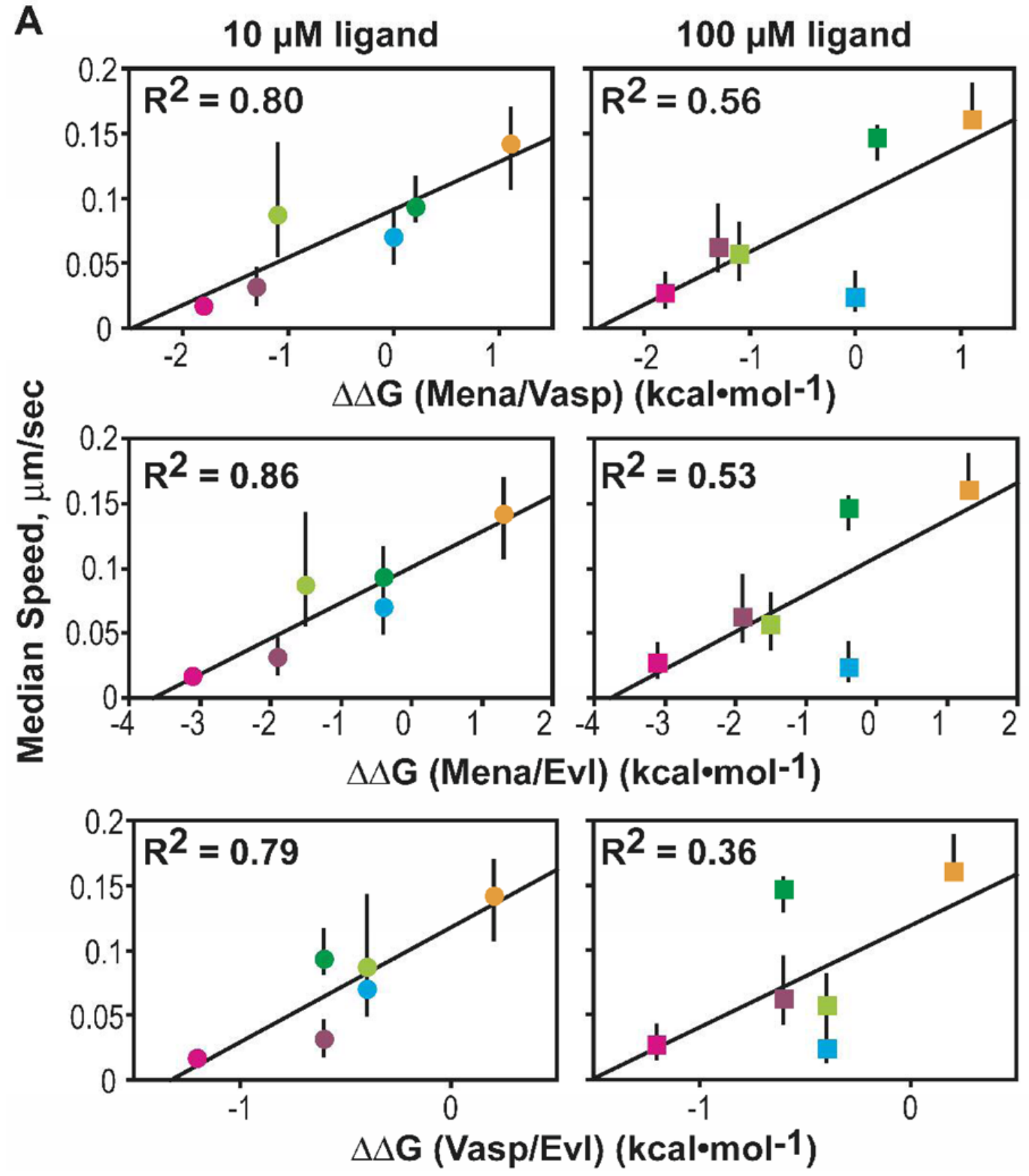
B

$10 \mu \mathrm{M}$ ligand

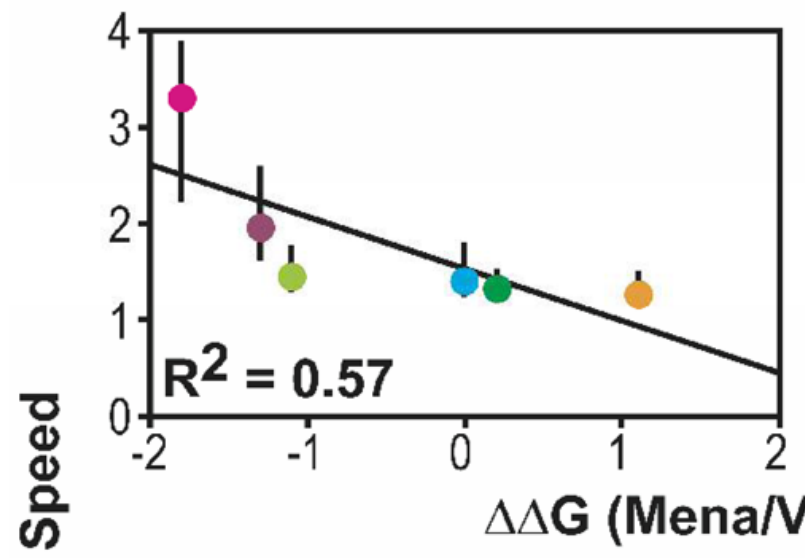

들

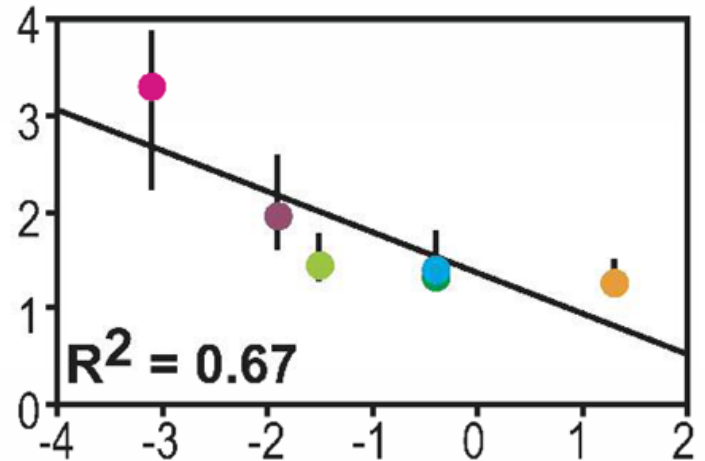

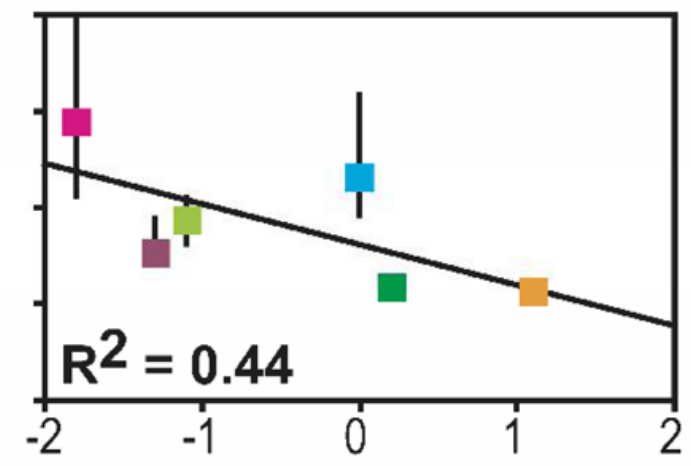

$100 \mu \mathrm{M}$ ligand

$\Delta \Delta \mathbf{G}$ (Mena/Evl) (kcal•mol-1)
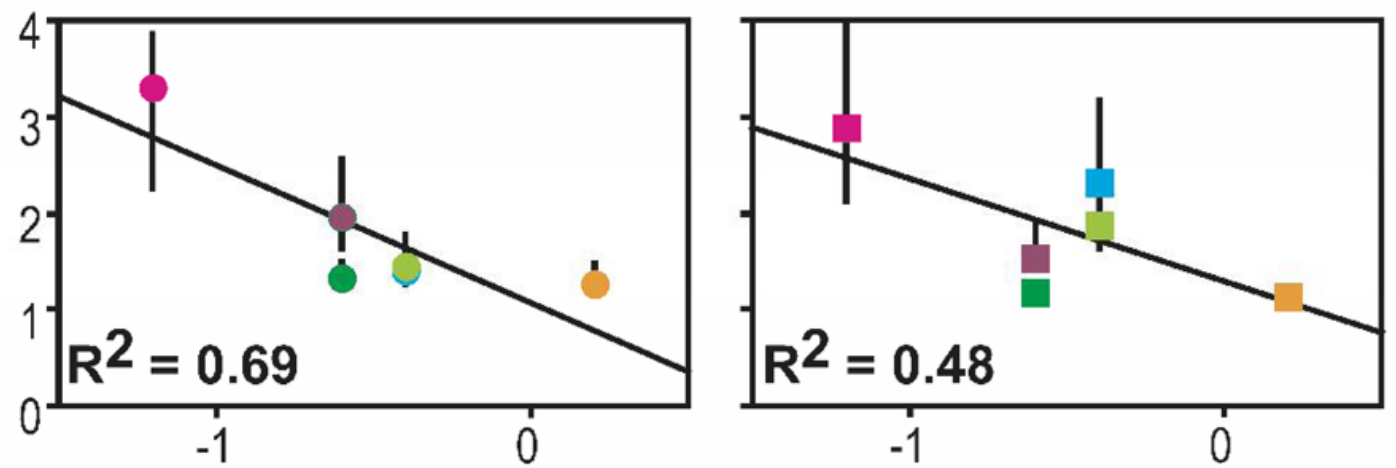

$\Delta \Delta \mathrm{G}$ (Vasp/Evl) (kcal•mol-1)

Figure 5.

Quantitative analysis of L. monocytogenes motility as a function of EVH1 domain specificity. Plots of (A) median speed and (B) the ratio of the maximum to median speed in the presence of 10 or $100 \mu \mathrm{M}$ miniature protein as a function of EVH1 domain specificity. Error bars represent the $25^{\text {th }}(-)$ and $75^{\text {th }}(+)$ percentile of moving bacteria. 

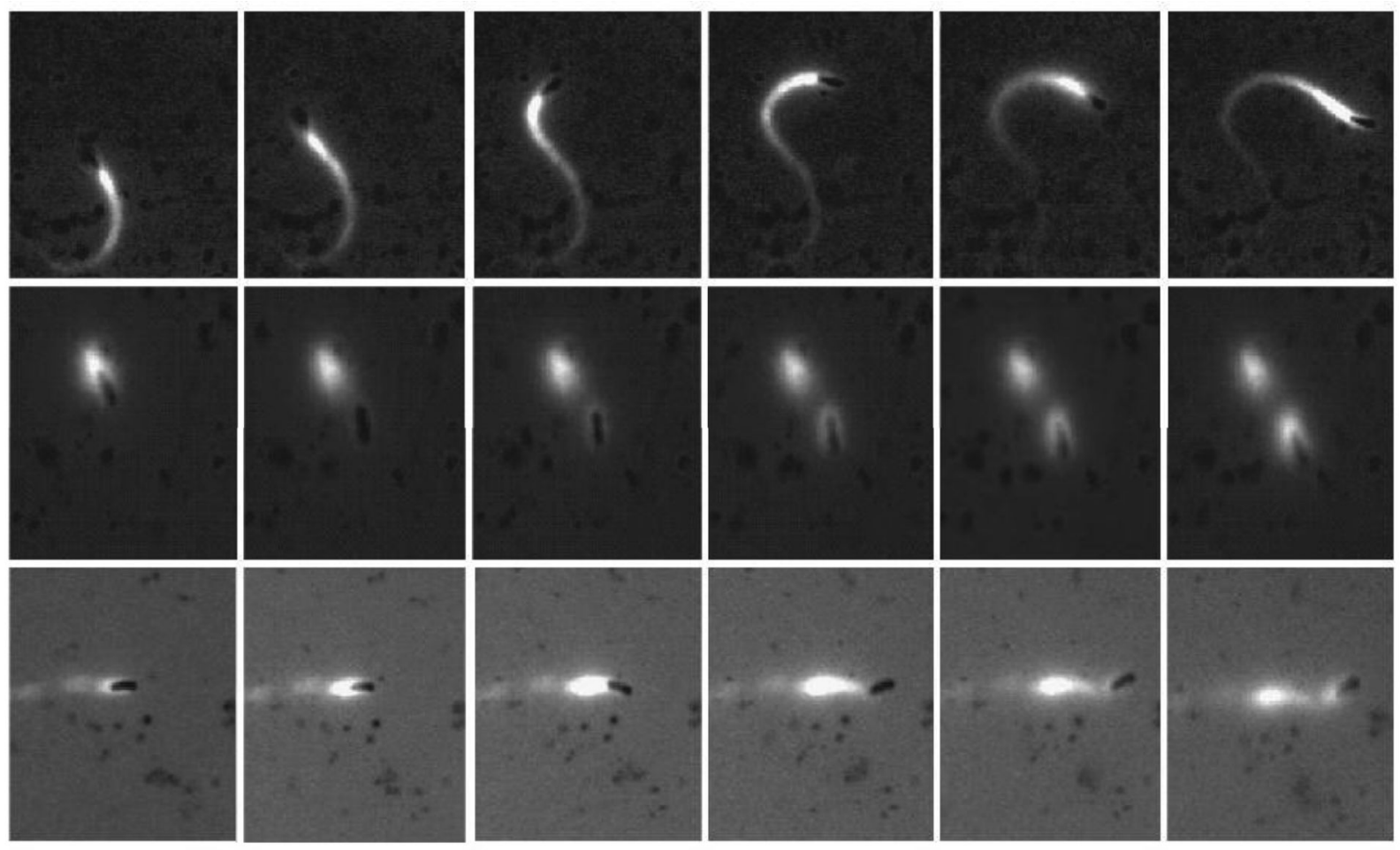

Figure 6.

Time-lapsed images of L. monocytogenes motility visualized using (A \& B) rhodamine-labeled phalloidin to visualize the actin cytoskeleton or $(\mathrm{C}) \mathrm{pGolemi}^{\mathrm{Flu}}$. Time-lapsed images were taken at 25 second intervals under fluorescence illumination. (A) In the absence of pGolemi, L. monocytogenes (black rods) move rapidly at steady state. (B) In the presence of $27 \mu \mathrm{M}$ pGolemi, L. monocytogenes move slowly and actin tails are discontinuous. (C) pGolemi ${ }^{\text {Flu }}$ (white) at $27 \mu \mathrm{M}$ is integrated into the actin tail in a discontinuous pattern. 
$\mathbf{A}$
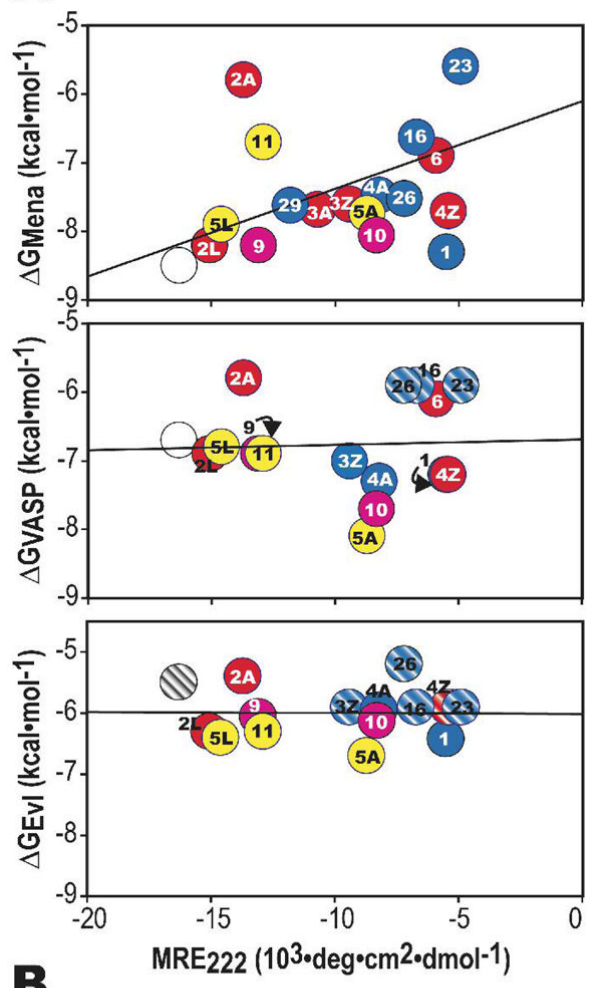

B
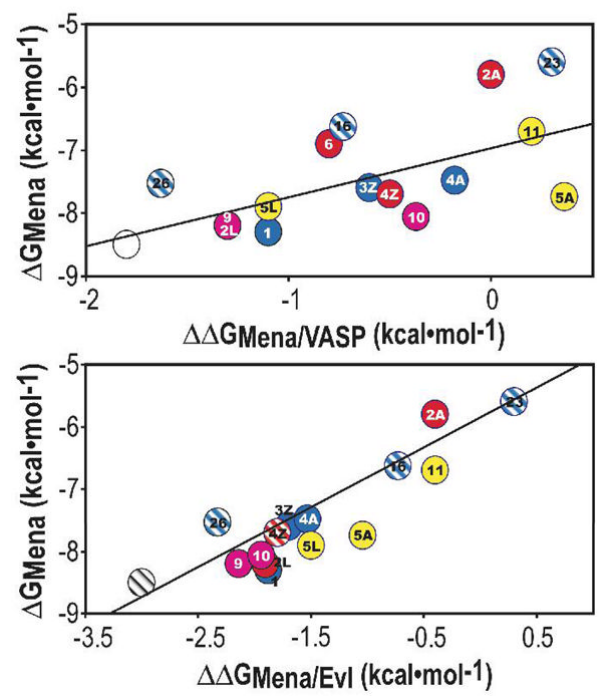

Figure 7.

Relationship between $(\mathrm{A})$ miniature protein secondary structure $\left(\Theta_{\mathrm{MRE}}\right)$ and binding free energy of complexes with Mena $1-112, \mathrm{VASP}_{1-115}$ and $\mathrm{Evl}_{1-115}$. (B) Relationship between the affinity of a miniature protein for Mena $\mathrm{M}_{1-12}$ or $\mathrm{VASP}_{1-115}$ and either $\mathrm{Mena}_{1-112} / \mathrm{VASP}_{1-115}$ or $\mathrm{Mena}_{1-112} / \mathrm{Evl}_{1-115}$ specificity. Letters represent the amino acid substituted at the position shown. Variants containing substitutions derived from ActA are shown in red (FP4 core) or pink (flanking acidic residues). Variants containing substitutions derived from aPP are shown in blue. Other variants are in yellow. pGolemi is shown in white. Stripes represent variants for which only a lower limit of affinity was determined. 


\section{L. monocytogenes motility vs. time}
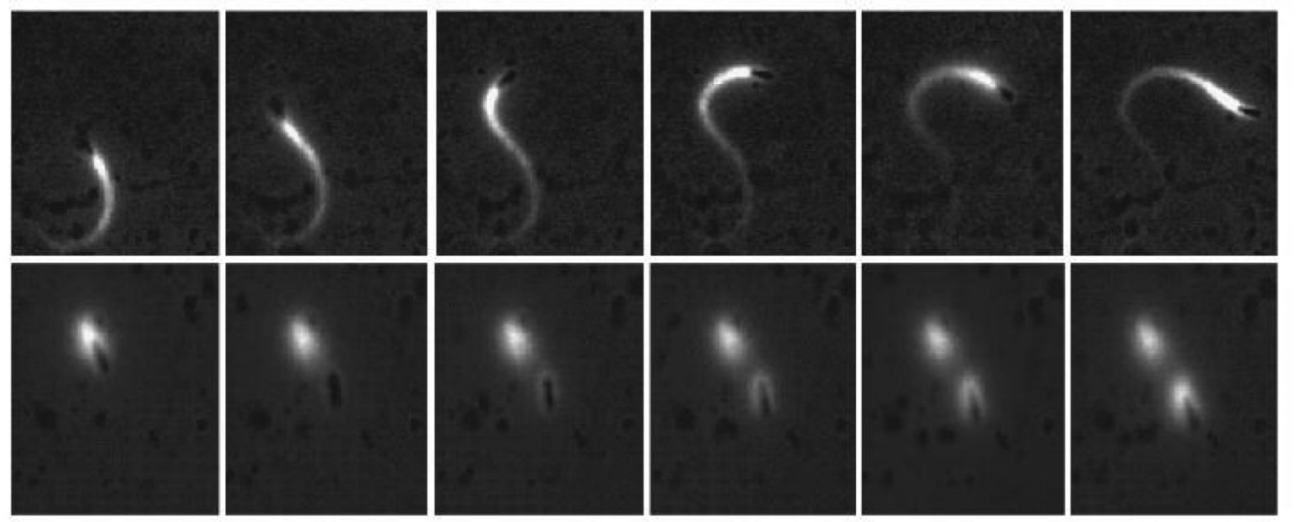

miniature protein

TOC graphic. 


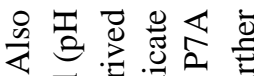
ن चु in $z$

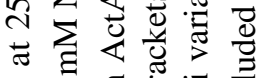
으의 근

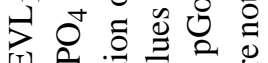

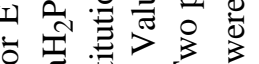

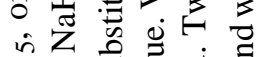

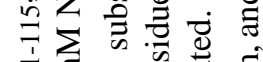

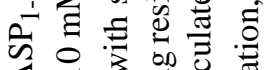

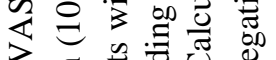

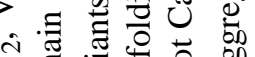

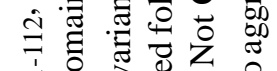

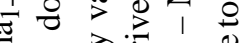

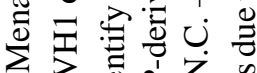

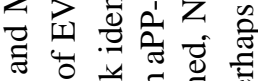

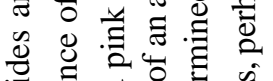
运

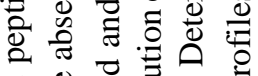

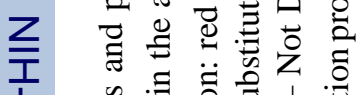
i

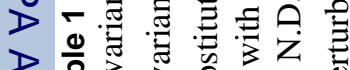

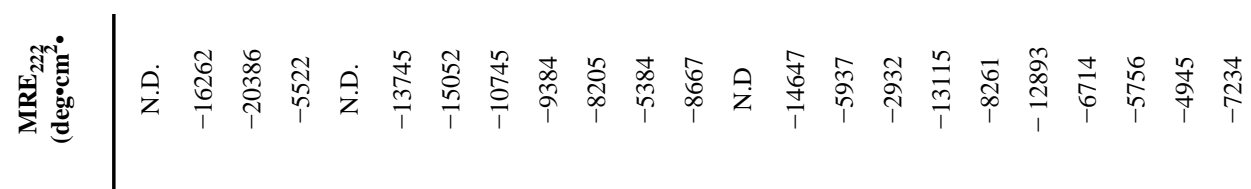

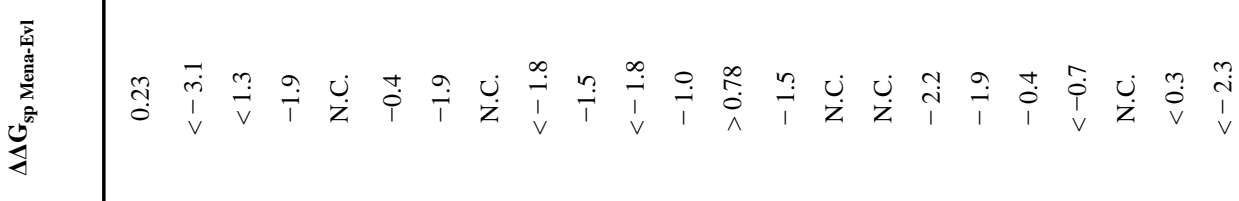

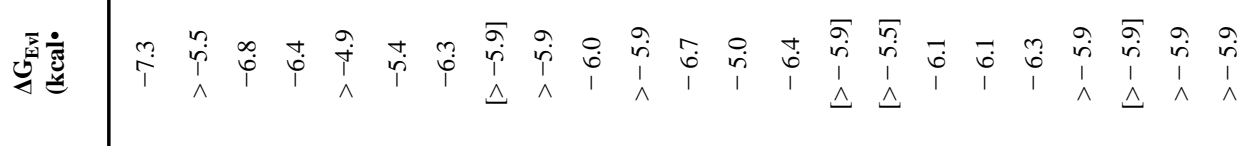

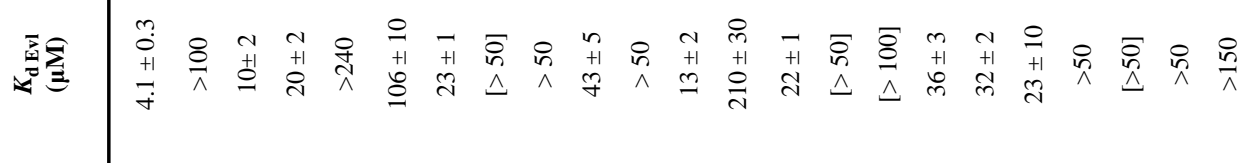

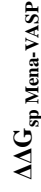

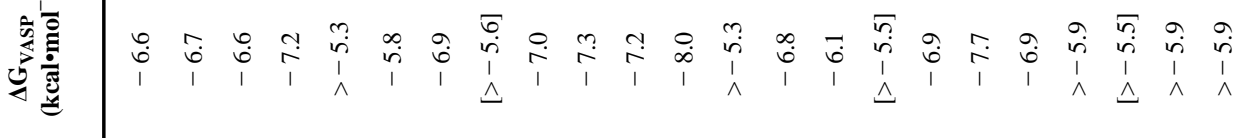

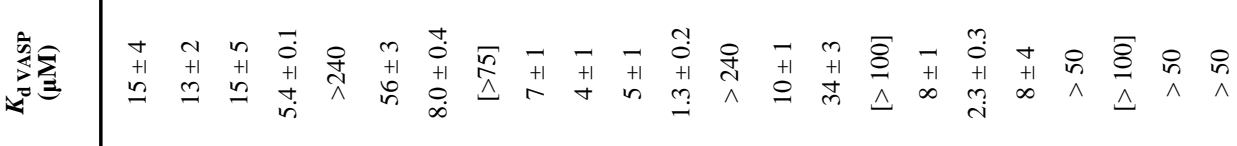

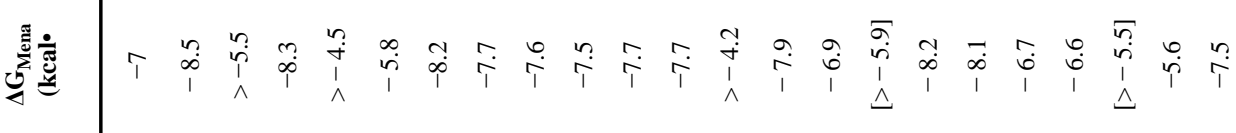

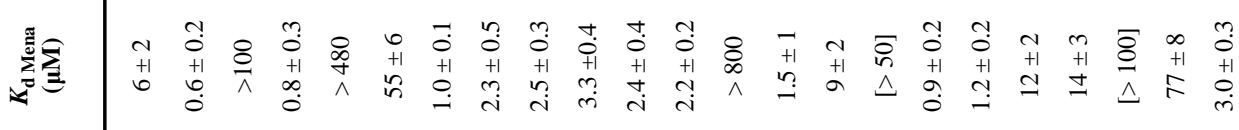

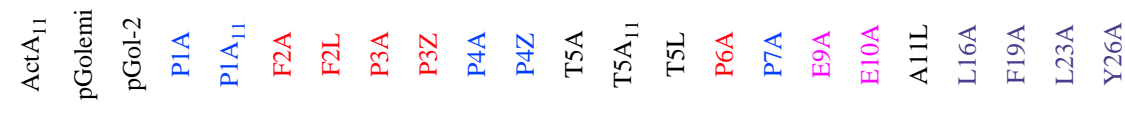




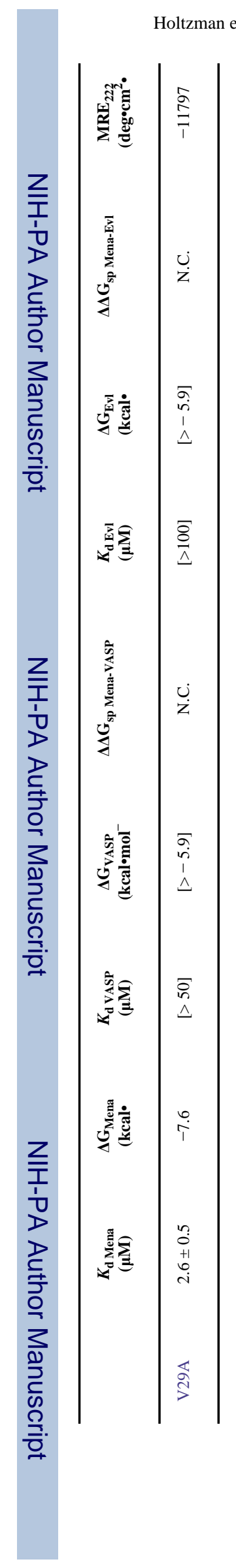

Page 30 